\title{
The Importance of the Montreal Protocol in Protecting Earth's Hydroclimate
}

\author{
YUTIAN WU \\ Courant Institute of Mathematical Sciences, New York University, New York, New York \\ LORENZO M. POLVANI \\ Department of Applied Physics and Applied Mathematics and Department of Earth and Environmental Sciences, \\ Columbia University, New York, New York \\ RICHARD SEAGER \\ Lamont-Doherty Earth Observatory, Columbia University, Palisades, New York
}

(Manuscript received 17 September 2012, in final form 9 December 2012)

\begin{abstract}
The 1987 Montreal Protocol regulating emissions of chlorofluorocarbons (CFCs) and other ozonedepleting substances (ODSs) was motivated primarily by the harm to human health and ecosystems arising from increased exposure to ultraviolet-B (UV-B) radiation associated with depletion of the ozone layer. It is now known that the Montreal Protocol has helped reduce radiative forcing of the climate system since CFCs are greenhouse gases (GHGs), and that ozone depletion (which is now on the verge of reversing) has been the dominant driver of atmospheric circulation changes in the Southern Hemisphere in the last half century.

This paper demonstrates that the Montreal Protocol also significantly protects Earth's hydroclimate. Using the Community Atmospheric Model, version 3 (CAM3), coupled to a simple mixed layer ocean, it is shown that in the "world avoided" (i.e., with CFC emissions not regulated), the subtropical dry zones would be substantially drier, and the middle- and high-latitude regions considerably wetter in the coming decade (202029 ) than in a world without ozone depletion. Surprisingly, these changes are very similar, in both pattern and magnitude, to those caused by projected increases in GHG concentrations over the same period. It is further shown that, by dynamical and thermodynamical mechanisms, both the stratospheric ozone depletion and increased CFCs contribute to these changes. The results herein imply that, as a consequence of the Montreal Protocol, changes in the hydrological cycle in the coming decade will be only half as strong as what they otherwise would be.
\end{abstract}

\section{Introduction}

The depletion of the stratospheric ozone layer was one of the major scientific and environmental issues of the twentieth century. The hypothesis of man-made chlorofluorocarbons (CFCs) and other ozone depleting substances (ODSs) as a major threat to stratospheric ozone dates back to Molina and Rowland (1974). The first observational evidence was reported in Farman et al. (1985), which found large ozone losses in austral spring over the Antarctic at the British Antarctic Survey

Corresponding author address: Yutian Wu, Courant Institute of Mathematical Sciences, New York University, New York, NY 10012.

E-mail: yutian@cims.nyu.edu station. Since stratospheric ozone absorbs most of the solar ultraviolet-B (UV-B) radiation reaching Earth's surface, the destruction of the ozone layer has been linked to significant environmental and public-health consequences such as cataracts and skin cancers and damage to crops and to marine phytoplankton (e.g., WMO 2011; Andrady et al. 2012, and references therein). To protect human health as well as the environment from the damaging effects of exposure to UV-B radiation, the Montreal Protocol on Substances that Deplete the Ozone Layer was adopted in 1987 to phase out the production of CFCs and other ODSs.

The successful implementation of the 1987 Montreal Protocol and its Amendments has had a marked effect on ODSs and the stratospheric ozone layer. The concentrations of most ODSs have been declining after 
reaching a peak in the 1990s (Montzka et al. 1999; Mäder et al. 2010), and there are perhaps signs of the onset of ozone layer recovery in the past decade (e.g., Newchurch et al. 2003; Reinsel et al. 2002, 2005; Yang et al. 2006, 2008; Salby et al. 2011, 2012). Furthermore, since the ODSs are also greenhouse gases (GHGs), their elimination has helped reduce radiative forcing of Earth's climate by approximately $0.8-1.6 \mathrm{~W} \mathrm{~m}^{-2}$ by 2010 , which is, in fact, substantially larger than the reduction target of the first commitment period of the Kyoto Protocol (Velders et al. 2007). As also reported by Velders et al. (2007), this compares to the radiative forcing due to anthropogenic $\mathrm{CO}_{2}$ increase since preindustrial times under the Intergovernmental Panel on Climate Change Fourth Assessment Report (IPCC AR4) A1B scenario of about $1.8 \mathrm{~W} \mathrm{~m}^{-2}$ in 2010.

In addition, changes in the stratospheric ozone layer also significantly modify the atmospheric general circulation. Polvani et al. (2011b) and McLandress et al. (2011) found that, over the second half of the twentieth century, most of the tropospheric circulation changes in the Southern Hemisphere during summer-for example, the poleward shift of the zonal mean zonal wind and the hydrological cycle in the middle and high latitudeswere caused by the polar stratospheric ozone loss over Antarctica. Kang et al. (2011) showed that the polar stratospheric ozone loss is also responsible for the observed subtropical moistening in austral summer from 1979 to 2000 . On the other hand, the anticipated stratospheric ozone recovery in the coming half century, due to the implementation of the Montreal Protocol, will result in a large cancellation of the effects of increased GHGs on atmospheric circulation in the Southern Hemisphere (Perlwitz et al. 2008; Son et al. 2008; Polvani et al. 2011a; McLandress et al. 2011).

In this paper, we demonstrate that the implementation of the Montreal Protocol has also been critical in protecting the entire Earth hydroclimate. We show this by calculating, with an IPCC AR4-class atmospheric general circulation model (AGCM), the changes in the hydrological cycle and the atmospheric general circulation under the "world avoided" (WA) scenario, in which the CFCs and other ODSs had not been regulated. Such scenarios have been considered before, but the main focus to date has been limited to ozone, specifically its dramatic depletion and impact on the stratosphere in the absence of a protocol to limit ODSs.

Newman et al. (2009) recently used the Goddard Earth Observing System (GEOS) chemistry-climate model to calculate the ozone distribution in the absence of the Montreal Protocol, assuming the CFCs and other ODSs grow at an annual rate of $3 \%$, and with the A1B scenario (Nakicenovic and Swart 2000) for other well-mixed
GHGs $\left(\mathrm{CO}_{2}, \mathrm{CH}_{4}\right.$, and $\left.\mathrm{N}_{2} \mathrm{O}\right)$. In their WA integration, $17 \%$ of total ozone is destroyed by 2020 in the global average compared to the 1980 level, and an ozone hole starts to form each year over the Arctic. By 2065, 67\% of the ozone is depleted globally, and ozone hole-type conditions become global and year-round, rather than being only predominant over Antarctica and confined to austral spring. Other recent studies have also performed WA simulations and documented some surface impacts, but with other chemistry-climate models (e.g., Morgenstern et al. 2008; Egorova et al. 2012; Garcia et al. 2012); to date, none has focused on the hydroclimate impacts.

In this paper, we focus on the coming decade (202029) and explore how the increase in CFCs and decrease in stratospheric ozone in the WA scenario impact the global hydroclimate. As shown below, in the world avoided, the subtropical dry regions become drier and the middle- and high-latitude wet regions become wetter. Furthermore, these changes are of comparable magnitude and show similar patterns to changes associated with the increase of major GHGs $\left(\mathrm{CO}_{2}, \mathrm{CH}_{4}\right.$, and $\mathrm{N}_{2} \mathrm{O}$ ) from 1960 to the 2020-29 levels, as well as to the changes projected by the transient Coupled Model Intercomparison Project, phases 3 and 5 (CMIP3 and CMIP5, respectively), anthropogenic climate change integrations over identical periods. Because these impacts of ozone depletion on hydroclimate were not known until now, the absence of such is a benefit of the 1987 Montreal Protocol that appears to be entirely fortuitous.

To better understand the dynamical mechanisms underlying the hydrological cycle change in the WA scenario, we also separate the effects of stratospheric ozone depletion and CFC increase by individually specifying the two forcings, using the same general circulation model configuration. The AGCM used in this study lacks interactive chemistry: concentrations of CFCs and ozone are specified as external forcings and do not change with the modeled climate, which allows us to individually impose the ozone depletion and the CFC increase. We find that, in the coming decade, the hydrological cycle response in the tropics and the Northern Hemisphere (NH) for the WA scenario is largely caused by the CFC increase, whereas in the Southern Hemisphere $(\mathrm{SH})$ both stratospheric ozone depletion and CFC increase contribute substantially. In addition, in order to determine exactly how and why the hydrological cycle is altered in the WA scenario, the changes in zonal mean atmospheric moisture budget are decomposed into contributions from changes in specific humidity, mean meridional circulation, and transient eddy moisture flux convergence. 
Here is the outline of this paper. In section 2, we describe the climate model integrations used in this study. In section 3, we present the changes in the hydrological cycle and zonal mean atmospheric general circulation in the WA scenario from our climate model integrations. As a comparison, results for an equilibrium increased GHGs scenario using the same model configuration, and for the transient CMIP3 and CMIP5 coupled climate model projections over identical periods, are also presented. Section 4 discusses the attributions of individual contributions to the hydrological cycle change from stratospheric ozone depletion and CFC increases. The thermodynamic and dynamic components of the changes are also analyzed in section 4. A discussion and conclusions close the paper in section 5 .

\section{Climate model integrations}

The general circulation model used in this study is the National Center for Atmospheric Research (NCAR) Community Atmospheric Model, version 3 (CAM3; Collins et al. 2006). The model is integrated at a spectral T42 horizontal resolution (approximately $2.8^{\circ} \times 2.8^{\circ}$ in latitude and longitude), with 26 vertical levels on a hybrid vertical coordinate and a model top at about $2.9 \mathrm{mb}$. The atmospheric component is coupled to a slab ocean model, and a thermodynamic sea ice model, where the sea surface temperatures (SSTs) only adjust to surface energy imbalance. The equilibrium climate sensitivity of this model is about $2.2 \mathrm{~K}$ in response to a doubling of $\mathrm{CO}_{2}$, and the doubled $\mathrm{CO}_{2}$ forcing is estimated to be $3.33 \mathrm{~W} \mathrm{~m}^{-2}$ (Wu et al. 2012). Since CAM3 does not have a prognostic chemistry module, GHG and ozone concentrations can be specified independently. A version of CAM3 with higher horizontal resolution (spectral T85) was used in the Community Climate System Model, version 3 (CCSM3), which is a fully coupled atmosphere-ocean climate model that participated in the CMIP3 intercomparison project. As evaluated in Reichler and Kim (2008), the CCSM3 is one of the wellperforming coupled climate models for simulating the present-day climate.

To understand the impact of the Montreal Protocol on Earth's hydrological cycle, a pair of so-called time-slice experiments was performed using this model. Each experiment comprises an ensemble of 30 members, each member consisting of a 30-yr-long model integration; this length was chosen to ensure that the model's climate reaches radiative equilibrium (see below). Ensemble members were generated using slightly perturbed initial conditions, which were taken from the same day in different years from a long control integration.
For the first experiment (REF1960), the concentrations of $\mathrm{CO}_{2}, \mathrm{CH}_{4}, \mathrm{~N}_{2} \mathrm{O}, \mathrm{CFC}-11$, and CFC-12 as well as the ozone field were prescribed at levels corresponding to the year 1960. As in Polvani et al. (2011b), the ozone used in these integrations was taken from Cionni et al. (2011).

For the second experiment (WA2025), the concentrations of CFC-11, CFC-12, and stratospheric ozone ${ }^{1}$ were changed from the reference 1960 level to the WA values, averaged over the decade 2020-29. It is important to recall that, in addition to their effect on ozone, CFCs are also major GHGs: thus including both CFC increases and the ozone depletion they caused is the consistent way to explore the WA scenario. Also, in order to specifically isolate the effects of the Montreal Protocol, other major GHGs such as $\mathrm{CO}_{2}, \mathrm{CH}_{4}$, and $\mathrm{N}_{2} \mathrm{O}$ were kept fixed at the reference 1960 level in the WA2025 integrations. For complete reproducibility, the values and datasets used in our experiments are explicitly given in Table 1 .

In many figures below, the effect of the Montreal Protocol is illustrated as the difference between the equilibrated WA2025 and the REF1960 experiments. For each experiment, the 30 ensemble members are first averaged together, and these averages are then subtracted. To show the equilibrated results, only the average of the last 10 years is used for each model integration.

To offer a quantitative point of reference and better appreciate the effect of the Montreal Protocol on the hydrological cycle and the atmospheric circulation, we have conducted an additional experiment to estimate the effect of increased GHGs, over identical periods, and using the same model configuration: this is called GHG2025 hereafter. The major GHG concentrations $\left(\mathrm{CO}_{2}, \mathrm{CH}_{4}\right.$, and $\left.\mathrm{N}_{2} \mathrm{O}\right)$ were changed to the A1B scenario during 2020-29 while keeping the CFCs and ozone at the reference 1960 level. In the GHG2025 experiment, the concentrations of $\mathrm{CO}_{2}, \mathrm{CH}_{4}$, and $\mathrm{N}_{2} \mathrm{O}$ increase by approximately $37 \%, 66 \%$, and $15 \%$, respectively, relative to the 1960 level, and the precise values of all forcings and datasets used are provided in Table 1. As above, the GHG2025 experiment has in total 30 ensemble members, each integrated for 30 years to equilibrium, with the averages of the last 10 years representing the equilibrium results. This allows for perfectly identical statistics,

\footnotetext{
${ }^{1}$ We take our WA ozone from Newman et al. (2009), and impose the ozone changes (to the REF1960 values) in the stratosphere only. Tropospheric ozone changes, possibly associated with increasing pollution, were found not to be important in determining the circulation response and, for simplicity, were excluded from the experiments presented here.
} 
TABLE 1. The six model experiments used in this study, and their respective forcings. All experiments were performed using the NCAR CAM3 coupled to a slab ocean model, and each consists of an ensemble of 30 model runs, each integrated to equilibrium. Note that ozone concentrations are prescribed, in CAM3, with time variations associated with the seasonal cycle, but this cycle is unchanged from one year to the next.

\begin{tabular}{|c|c|c|c|c|c|c|}
\hline Experiment & $\begin{array}{c}\mathrm{CO}_{2} \\
\left(\times 10^{-6}\right)\end{array}$ & $\begin{array}{c}\mathrm{CH}_{4} \\
\left(\times 10^{-9}\right)\end{array}$ & $\begin{array}{c}\mathrm{N}_{2} \mathrm{O} \\
\left(\times 10^{-9}\right)\end{array}$ & $\begin{array}{c}\text { CFC-11 } \\
\left(\times 10^{-12}\right)\end{array}$ & $\begin{array}{l}\text { CFC-12 } \\
\left(\times 10^{-12}\right)\end{array}$ & Ozone \\
\hline REF1960 & 317 & 1271 & 291 & 9 & 30 & AC\&C/SPARC ozone at $1960^{*}$ \\
\hline WA2025 & 317 & 1271 & 291 & 1256 & 2296 & World avoided (2020-29 mean)** \\
\hline GHG2025 & 435 & 2106 & 334 & 9 & 30 & AC\&C/SPARC ozone at 1960 \\
\hline ALL2025 & 435 & 2106 & 334 & 1256 & 2296 & World avoided (2020-29 mean)** \\
\hline OZONE2025 & 317 & 1271 & 291 & 9 & 30 & World avoided (2020-29 mean) \\
\hline CFC2025 & 317 & 1271 & 291 & 1256 & 2296 & AC\&C/SPARC ozone at 1960 \\
\hline
\end{tabular}

* Details of the Atmospheric Chemistry and Climate (AC\&C)/Stratospheric Processes and their Role in Climate (SPARC) ozone database can be found in Cionni et al. (2011).

** The ozone for WA2025 case is taken from the coupled chemistry-climate model integrations described in Newman et al. (2009).

so that we can unambiguously, and quantitatively, compare the greenhouse warming effect with the impact of the Montreal Protocol within, of course, the limitations of the CAM3 coupled to a slab ocean model.

To transcend those limitations, we also present results from the multimodel ensemble of the global climate models from CMIP3 (Meehl et al. 2007) and CMIP5 (Taylor et al. 2012). For CMIP3, 24 models were used (see Table 2 for details) and the response is defined as the difference between the A1B scenario (averaged over 2020-29) and the twentieth-century simulations (20C3M), averaged over 1955-64. For CMIP5, 18 models with available output of surface temperature (TS), precipitation $(P)$ and evaporation $(E)$ were used (see Table 3 for details) and the global warming response is calculated as the difference between the Representative Concentration Pathway 4.5 (RCP4.5) scenario ${ }^{2}$ and the "historical" simulations, averaged over identical periods to the CMIP3 models. It is important to keep in mind, when comparing the WA changes with those of the CMIP models, that the latter are transient integrations whereas the former are equilibrium responses. Nonetheless, since the transient response typically constitutes a large fraction of the equilibrium response

\footnotetext{
${ }^{2}$ The Special Report on Emissions Scenarios (SRES) A1B scenario in CMIP3 gradually increases and doubles the $\mathrm{CO}_{2}$ concentration at the end of the twenty-first century. The radiative forcing is approximately $6.0 \mathrm{~W} \mathrm{~m}^{-2}$ in 2100 (see Fig. 10.26 in Solomon et al. 2007). The integrations in CMIP5 adopt a new set of scenarios for climate change research: the representative concentration pathways (RCPs). The RCP4.5 is the medium-low scenario where the anthropogenic radiative forcing increases and stabilizes at about $4.5 \mathrm{~W} \mathrm{~m}^{-2}$ in 2150 (Meinshausen et al. 2011). However, during 2020-29, the A1B and the RCP4.5 scenarios have approximately the same $\mathrm{CO}_{2}$ concentration $(435 \mathrm{ppmv})$ and radiative forcing $\left(3.0 \mathrm{~W} \mathrm{~m}^{-2}\right)$.
}

(see, e.g., Table 8.2 in Solomon et al. 2007), this comparison is meaningful, if not quantitatively exact.

Furthermore, in order to explain the additivity of the WA2025 and the GHG2025 forcings, another experiment was performed using the NCAR CAM 3 coupled to a slab ocean model with all the forcings averaged over 2020-29 (called ALL2025 hereafter) - that is, with the 2020-29 mean GHG concentrations and the WA CFC11, CFC-12, and ozone fields (see Table 1 for detailed information). Finally, in the WA2025 experiment, we expect both the stratospheric ozone depletion and increased CFCs to contribute to the hydroclimate change. To isolate the individual effects of the stratospheric ozone depletion and CFC increase, two additional separate experiments were performed. One of the experiments, OZONE2025, only modifies the ozone field to that of the WA scenario, while the other experiment, CFC2025, changes the CFC-11 and CFC-12 to the 2020-29 mean values alone (see Table 1 for detailed information).

\section{Hydroclimate changes in the world avoided}

It may be useful to start by recalling that, in the WA scenario, during 2020-29, stratospheric ozone depletion occurs at all latitudes, even in the NH, as shown in Fig. 1a (black dashed contours). As a consequence of this ozone loss, the zonal mean equilibrium temperature in the lower stratosphere-shown in color in Fig. 1a-is substantially reduced, especially in the $\mathrm{SH}$ high latitudes (by about $6 \mathrm{~K}$ ), in the tropics (by about $2-4 \mathrm{~K}$ ), and, to a lesser extent, in the NH high latitudes (by about $1-2 \mathrm{~K}$ ). A warming of approximately $1-2 \mathrm{~K}$ is found in the tropical upper troposphere, owing to the greenhouse warming effect associated with increased CFCs (to be discussed in section 4a below). The tropopause height also rises globally, corresponding to 
TABLE 2. The 24 models used from CMIP3 are listed below. Multimodel averages for CMIP3 were taken among these 24 models, using run 1 from each model except for the MIROC3.2(medres) where run 2 was used.

\begin{tabular}{|c|c|}
\hline Model & Expansion \\
\hline BCCR-BCM2.0 & Bjerknes Centre for Climate Research (BCCR) Climate Model, version 2.0 \\
\hline CCSM3 & Community Climate System Model, version 3 \\
\hline CGCM2.1(T47) & $\begin{array}{l}\text { Canadian Centre for Climate Modelling and Analysis (CCCma) Coupled General Circulation Model, } \\
\text { version } 2.1 \text { (T47) }\end{array}$ \\
\hline CGCM3.1(T63) & CCCma Coupled General Circulation Model, version 3.1 (T63) \\
\hline CNRM-CM3 & Centre National de Recherches Météorologiques (CNRM) Coupled Global Climate Model, version 3 \\
\hline CSIRO-Mk3.0 & Commonwealth Scientific and Industrial Research Organisation (CSIRO), Mark version 3.0 \\
\hline CSIRO-Mk3.5 & CSIRO, Mark version 3.5 \\
\hline ECHAM5/MPI-OM & ECHAM 5-Max Planck Institute Ocean Model \\
\hline ECHO-G & ECHAM and the global Hamburg Ocean Primitive Equation \\
\hline GFDL-CM2.0 & Geophysical Fluid Dynamics Laboratory (GFDL) Climate Model, version 2.0 \\
\hline GFDL-CM2.1 & GFDL Climate Model, version 2.1 \\
\hline GISS-AOM & Goddard Institute for Space Studies (GISS) Atmosphere-Ocean Model \\
\hline GISS-EH & GISS Model E-H \\
\hline GISS-ER & GISS Model E-R \\
\hline IAP-FGOALS-g1.0 & $\begin{array}{l}\text { Institute of Atmospheric Physics Flexible Global Ocean-Atmosphere-Land System Model gridpoint } \\
\text { version } 1.0\end{array}$ \\
\hline INGV-SXG & Istituto Nazionale di Geofisica e Vulcanologia Model SXG \\
\hline INM-CM3.0 & Institute of Numerical Mathematics (INM) Coupled Model, version 3.0 \\
\hline IPSL CM4 & L'Institut Pierre-Simon Laplace Coupled Model (IPSL), version 4 \\
\hline MIROC3.2(hires) & Model for Interdisciplinary Research on Climate (MIROC) 3.2, high-resolution version \\
\hline MIROC3.2(medres) & MIROC 3.2, medium-resolution version \\
\hline MRI-CGCM2.3.2 & Meteorological Research Institute (MRI) Coupled General Circulation Model, version 2.3.2a \\
\hline PCM & Parallel Climate Model \\
\hline UKMO-HadCM3 & third climate configuration of the Met Office Unified Model \\
\hline UKMO-HadGEM1 & Met Office Hadley Centre Global Environmental Model, version 1 \\
\hline
\end{tabular}

the simultaneous tropospheric warming and stratospheric cooling.

In the GHG2025 scenario, as shown in Fig. 1b for comparison, the troposphere warms (by about $2-3 \mathrm{~K}$ in the tropical upper troposphere), the stratosphere cools, and the tropopause height also increases. Note that, unlike in the WA response, stratospheric cooling due to rising GHGs increases with height in the upper atmosphere.

The adjustment of the energy budget at the top of the atmosphere (TOA) also shows similarities between the WA and the increased GHG scenarios (Fig. 2). Immediately after the increase of GHGs, the TOA outgoing longwave radiation (OLR) decreases by about $1.5 \mathrm{~W} \mathrm{~m}^{-2}$ in the global average (shown in Fig. 2b). At the same time, the net incoming solar radiation increases by about $0.5 \mathrm{~W} \mathrm{~m}^{-2}$ at the TOA, possibly due to a rapid decrease in low and midlevel cloud cover that reduces the reflection of solar radiation back to space (not shown; Wyant et al. 2012). As a result, the energy imbalance at the TOA leads to a higher energy flux reaching the surface, gradually increasing the global surface temperature (also shown in Fig. 2b), which in turn causes the OLR to increase, until the radiative balance is restored. This takes about 10-20 years of model integration and the global surface temperature increases by about $1.3 \mathrm{~K}$ at equilibrium. For the WA experiment a similar evolution can be seen, with a clear decrease in OLR at the beginning of the integration, accompanied by a net incoming solar radiation increase. Both the surface and troposphere warm, and the radiative balance is restored after about 10-20 years of integration with an increase in surface temperature of about $0.8 \mathrm{~K}$. This is mostly dominated by the effect of the CFC increase (see the appendix), with stratospheric ozone depletion contributing little to surface warming.

The key point here is that, in the WA scenario the globally averaged surface temperature increases by about $0.8 \mathrm{~K}$ (similar to the value found in the CMIP3 and CMIP5 multimodel averages during 2020-29, which is approximately $1.1 \mathrm{~K}$ ). As shown in Fig. 3 , the horizontal distribution of the increase is also similar for the WA2025 and GHG2025 experiments. The surface temperature response is statistically significant across the entire globe for all the model integrations (as indicated by dots), except for parts of the North Atlantic Ocean and the Southern Ocean in the CMIP ensembles. Statistical significance in this study is evaluated with a simple Student's $t$ test, using the $95 \%$ confidence interval. In the WA scenario, the surface temperature increases globally, more over the continents than over the ocean, 
TABLE 3. Multimodel averages for CMIP5 were taken among the following 18 models, using run r1i1p1 from each model except for the CNRM-CM5 where r2i1p1 was used for the historical scenario and the IPSL-CM5A-LR where r2i1p1 was used for the RCP4.5 scenario. (Institutions already expanded in Table 2 are not expanded again here.)

\begin{tabular}{|c|c|}
\hline Model & Expansion \\
\hline BCC-CSM1.1 & $\begin{array}{l}\text { Beijing Climate Center Climate System } \\
\text { Model, version } 1.1\end{array}$ \\
\hline CanESM2 & CCCma Earth System Model, version 2 \\
\hline CCSM4 & $\begin{array}{l}\text { Community Climate System Model, } \\
\text { version } 3\end{array}$ \\
\hline CNRM-CM5 & $\begin{array}{l}\text { CNRM Coupled Global Climate Model, } \\
\text { version } 5\end{array}$ \\
\hline CSIRO-Mk3.6.0 & CSIRO, Mark version 3.6 \\
\hline GFDL-ESM2G & GFDL Earth System Model, version 2G \\
\hline GISS-E2-R & GISS Model E2-R \\
\hline HadCM3 & $\begin{array}{l}\text { third climate configuration of the Met } \\
\text { Office Unified Model }\end{array}$ \\
\hline HadGEM2-ES & $\begin{array}{l}\text { Met Office Hadley Centre Global } \\
\text { Environmental Model, version 2-ES }\end{array}$ \\
\hline INM-CM4 & INM Coupled Model, version 4 \\
\hline IPSL-CM5A-LR & $\begin{array}{l}\text { IPSL Coupled Model, version 5a } \\
\text { (low resolution) }\end{array}$ \\
\hline IPSL-CM5A-MR & $\begin{array}{l}\text { IPSL Coupled Model, version 5a } \\
\text { (medium resolution) }\end{array}$ \\
\hline MIROC5 & MIROC, version 5 \\
\hline MIROC-ESM & MIROC Earth System Model \\
\hline MIROC-ESM-CHEM & $\begin{array}{l}\text { MIROC Earth System Model with } \\
\text { chemistry }\end{array}$ \\
\hline MPI-ESM-LR & $\begin{array}{l}\text { Max Planck Institute Earth System } \\
\text { Model, low resolution }\end{array}$ \\
\hline MRI-CGCM3 & $\begin{array}{l}\text { MRI Coupled General Circulation } \\
\text { Model, version } 3\end{array}$ \\
\hline NorESM1-M & $\begin{array}{l}\text { Norwegian Climate Centre Earth } \\
\text { System Model, version 1-M }\end{array}$ \\
\hline
\end{tabular}

and is mainly due to the increase of CFCs (see the appendix). The surface temperature increases by about 1-2 K over the Antarctic, the Southern Ocean, Australia, South Africa, and South America, and also extensively over the NH continents with a polar warming of about $2-3 \mathrm{~K}$ at $\mathrm{NH}$ high latitudes. ${ }^{3}$ The warming pattern is similar to that of the increased GHG scenario, except the latter has a larger amplitude. Moreover, the WA result is also similar to the surface warming from the transient CMIP3 and CMIP5 integrations with large warming over the continents. There are differences over the Southern Ocean and the North Atlantic Ocean, where little warming occurs in coupled models, perhaps due to changing ocean circulation, which is not captured by our slab ocean model.

\footnotetext{
${ }^{3}$ CAM3 is coupled to a slab ocean model and a thermodynamic sea ice model in this study, and thus the model results in the Arctic may not be in total agreement with those in CMIP3 and CMIP5.
}

We now turn to the main focus of this paper: the equilibrium response in the hydrological cycle. Figure 4 is similar to Fig. 3 but shows the equilibrium responses in precipitation minus evaporation $(P-E)$ for the world avoided, the increased GHG scenarios, and the transient responses from the CMIP3 and CMIP5 integrations during 2020-29. The corresponding zonal averages are plotted in Fig. 5.

The key result of this paper, clearly seen in Figs. 4a and 5 , is that the stratospheric ozone loss and increased CFCs in the WA scenario during 2020-29 affect the hydroclimate not only in the $\mathrm{SH}$, but also in the tropics and the NH. The climatological positive $P-E$ region in the tropics gets narrower and stronger, with a large enhanced moistening near the equator. The subtropical dry regions in general become even drier, especially in the $\mathrm{NH}$ (see Fig. 5). In the middle and high latitudes, $P-E$ increases in both hemispheres and is also associated with a poleward displacement of the latitude of the highest $P-E$. These features are largely consistent among the ensemble runs (as indicated by dots). In fact, both the pattern and the magnitude of the $P-E$ response in the WA scenario are similar to the equilibrium response in the increased GHG scenario for 2020-29 (Fig. 4b). In comparison to the GHG2025 experiment, the WA2025 experiment shows a very similar moistening trend near the equator, slightly smaller trends toward drying in the $\mathrm{SH}$ subtropics, moistening in the NH middle and high latitudes, and a more pronounced poleward shift of the SH midlatitude wet regions (Fig. 5).

Next consider the $P-E$ changes from the CMIP3 and CMIP5 multimodel averages (shown in Figs. 4c,d and 5), which show the transient hydrological impacts due to the projected $37 \% \mathrm{CO}_{2}$ increase, and miscellaneous other changes in radiative forcing, during 2020-29 relative to 1960 (keep in mind that in the A1B and RCP4.5 scenarios, $\mathrm{CO}_{2}$ is not the only forcing that is changed). The CMIP3 and CMIP5 responses are in very good agreement with each other, both showing an enhanced $P-E$ around the equator, with a contraction in the $\mathrm{NH}$ tropics, a drying trend in the subtropics, and a moistening trend at middle and high latitudes for both hemispheres, all of which is largely consistent among different climate models (as indicated by dots). Such a "dry gets drier and wet gets wetter" response to global warming has been widely recognized, and is mainly due to the increased water vapor content in the atmosphere and thus increased moisture convergence/divergence (Held and Soden 2006). Modifications to this pattern occur as a result of circulation changes (Seager et al. 2007, 2010).

As shown in Fig. 5, the changes in the zonal mean hydrological cycle associated with the WA scenario have essentially the same pattern and magnitude as those 
(a) T anomalies (WA2025-REF1960)

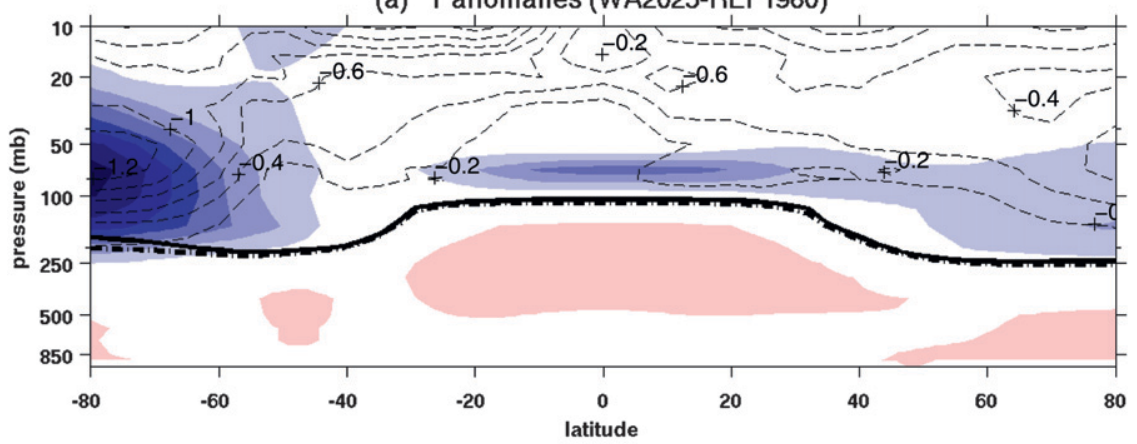

(b) T anomalies (GHG2025-REF1960)

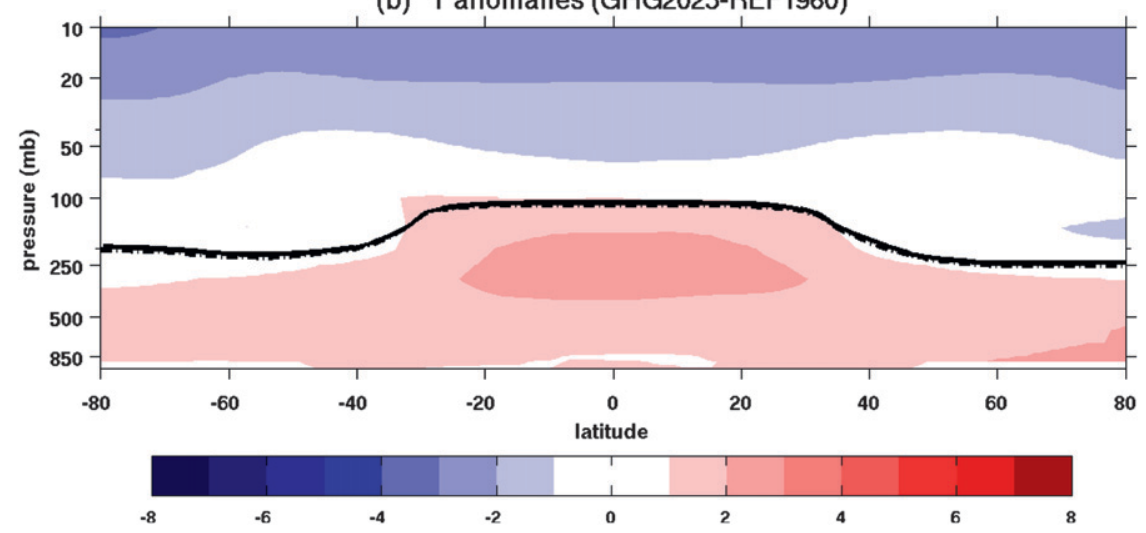

FIG. 1. Zonal and annual mean temperature response (color shadings; in K) in (a) the "world avoided" scenario (WA2025) and (b) the increased GHG scenario (GHG2025) during 2020-29 in comparison to the reference 1960 experiment (REF1960). In (a), the reduction in ozone field is plotted in thin dashed lines with contour intervals of $0.2 \mathrm{ppmv}$. Thick dash-dotted lines plot the tropopause height for the REF1960 experiment and thick solid lines for the WA2025 and the GHG2025 scenarios.

projected by the CMIP3 and CMIP5 multimodel averages for 2020-29 except for some minor differences. For example, the WA scenario has a larger $P-E$ response near the equator than that of the CMIP models, and this is likely due to the lack of ocean dynamics in our model, which tends to move the precipitation response away from the equator. Similarities are also observed between the increased GHG scenario and the transient CMIP integrations, supporting the relevance of the general circulation model and experimental configuration used in this study.

Figure 5 also shows the zonal mean $P-E$ response under the scenario of all the forcings averaged over 2020 29 (i.e., ALL2025 minus REF1960). Its large agreement with the sum of the responses in the WA ozone depletion and the increased GHG scenarios indicates the linear additivity of the forcings and suggests the large amplification of the hydrological cycle impacts in the coming decade in the absence of the Montreal Protocol. Therefore, the large similarities in the hydrological cycle response between the WA scenario and the increased GHG scenario suggest that, had the 1987 Montreal
Protocol not been ratified and implemented, the hydroclimate impact due to stratospheric ozone loss and CFC increases would have added onto that due to GHG increase, nearly doubling the trends of drying in the subtropics and moistening in the middle and high latitudes expected due to GHG increases alone.

The forcings accompanying the WA scenario also significantly alter the zonal mean circulation in the global atmosphere, in a way that is consistent with the change in the hydrological cycle. The left column of Fig. 6 shows the changes in the zonal mean zonal wind $\langle\bar{u}\rangle$, transient eddy momentum flux $\overline{\left\langle u^{\prime} v^{\prime}\right\rangle}$, mean meridional streamfunction $\langle\bar{\Psi}\rangle$, and vertical velocity $\langle\bar{\omega}\rangle$ between the WA2025 and the REF1960 experiments; for comparison, the results for the increased GHG scenario are shown in the right column. Bars and brackets denote time and zonal averages, respectively, and primes denote deviations from time averages.

Both the WA and increased GHG scenarios show a poleward shift of the tropospheric zonal jets in the SH midlatitudes, with a reduction of $\langle\bar{u}\rangle$ equatorward of $45^{\circ} \mathrm{S}$ and an intensification on the poleward side 
(a) TOA Energy Budget (WA2025-REF1960)

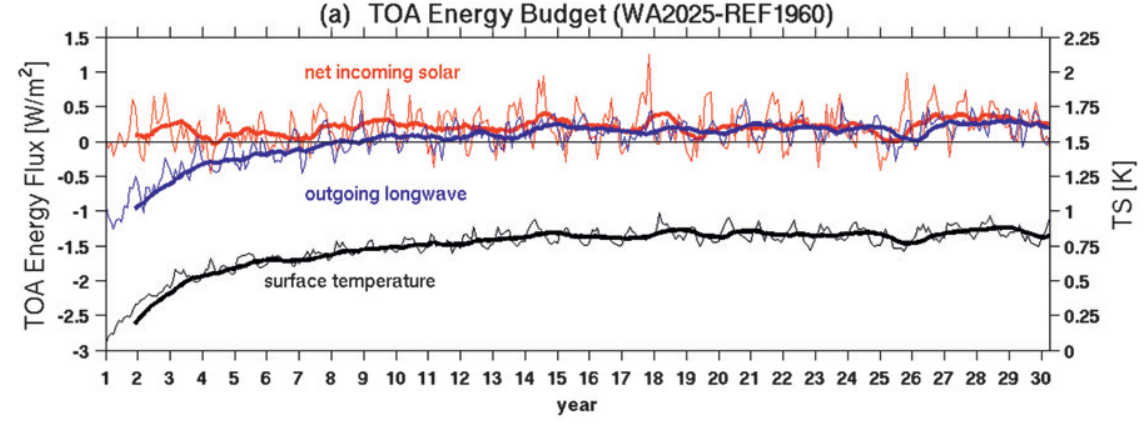

(b) TOA Energy Budget (GHG2025-REF1960)

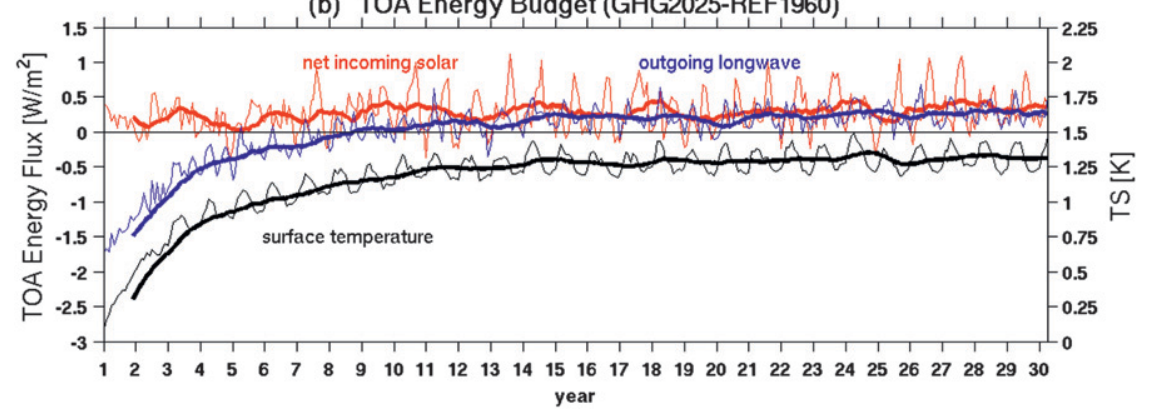

FIG. 2. Month-by-month evolution of global averaged net incoming solar radiation (red thin line) and outgoing longwave radiation (OLR; blue thin line) at the top of the atmosphere (TOA) for (a) the WA2025 minus REF1960 experiments and (b) the GHG2025 minus REF1960 experiments. The globally averaged surface temperature (TS) evolution (black thin line) is also plotted but on the right $y$ axis. Twelve-month running averages are shown in thick $\mathrm{red} / \mathrm{blue} / \mathrm{black}$ lines. Each curve is the average of 30 model integrations.

(Figs. 6a,b). The change in the zonal jet in the NH is much weaker in the troposphere, but shows an upward shift and an intensification of the lower stratospheric zonal wind. The response in $\left\langle\overline{u^{\prime} v^{\prime}}\right\rangle$ is similar, showing a poleward and upward shift as well as an intensification on the poleward flank of its climatological position (Figs. 6c,d). The Eulerian-mean streamfunction, shown in Figs. 6e and $6 \mathrm{f}$, and the vertical velocity, shown in Figs. $6 \mathrm{~g}$ and $6 \mathrm{~h}$, show an anomalous upward motion near the equator for both the WA and the greenhouse warming scenarios; this is in agreement with the $P-E$ increase in this region. Moreover, the zonal mean circulation weakens at its climatological maximum location in the tropics (i.e., $15^{\circ} \mathrm{S} / \mathrm{N}$ ), in particular for the greenhouse warming scenario, which indicates a weakening of the tropical Hadley cell (Vecchi and Soden 2007). Finally, one can see a poleward displacement of the subtropical subsidence region and of the middle- and high-latitude region of rising motion in both hemispheres: this is in agreement with the poleward shift of the extratropical hydrological cycle (Figs. 6g,h). Wu et al. (2012, 2013) explored the transient circulation adjustment after an instantaneous doubling of $\mathrm{CO}_{2}$ with the same model. They found that changes in stratospheric temperature and circulation from $\mathrm{CO}_{2}$ doubling can lead to a subsequent change in the tropospheric eddy field and mean circulation. It is possible, therefore, that the stratospheric ozone loss and CFC increases in the WA scenario affect the hydroclimate and the tropospheric circulation via similar mechanisms.

In summary, we have found that the equilibrium response of the hydrological cycle to the WA scenario during 2020-29 shows an enhanced moistening in the deep tropics and middle and high latitudes in both hemispheres, and a drying in the NH subtropics. This is, in fact, both qualitatively and quantitatively similar to the equilibrium response in the increased GHG scenario, and also in the transient response found in the CMIP3 and CMIP5 coupled climate models over identical periods. The zonal mean atmospheric circulation response in the WA scenario is also consistent with the response of the hydrological cycle, and is largely similar to that in the increased GHG scenario. These results suggest that, in the absence of the Montreal Protocol in 1987, the hydroclimate changes in the coming decade-drying in the subtropics and moistening in the middle to high latitudes-would have almost doubled those due to GHG increases alone.

For a better understanding of the mechanisms causing the hydroclimate response in the WA scenario, we next examine the relative contributions from stratospheric 
(a) TS Anomalies (WA2025-REF1960) $0.84 \mathrm{~K}$

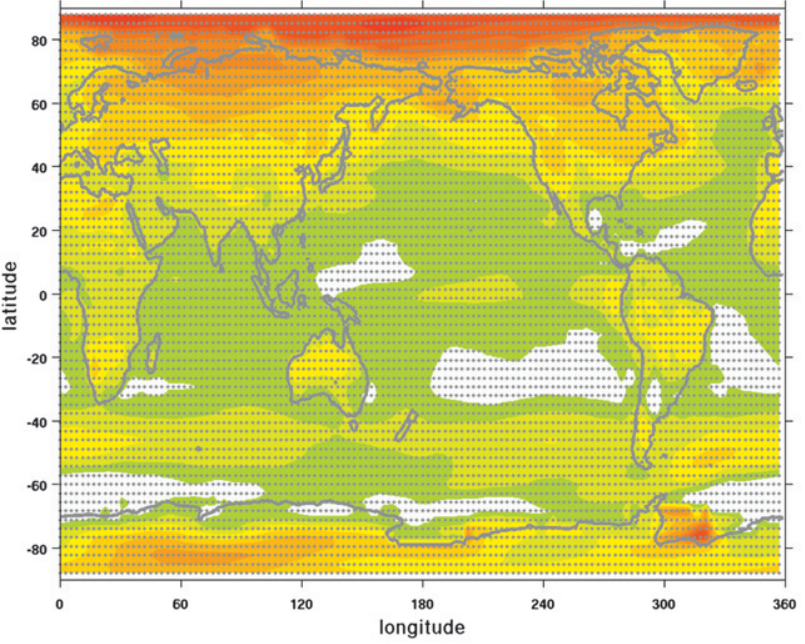

(c) TS Anomalies (CMIP3 2025-1960) $1.08 \mathrm{~K}$

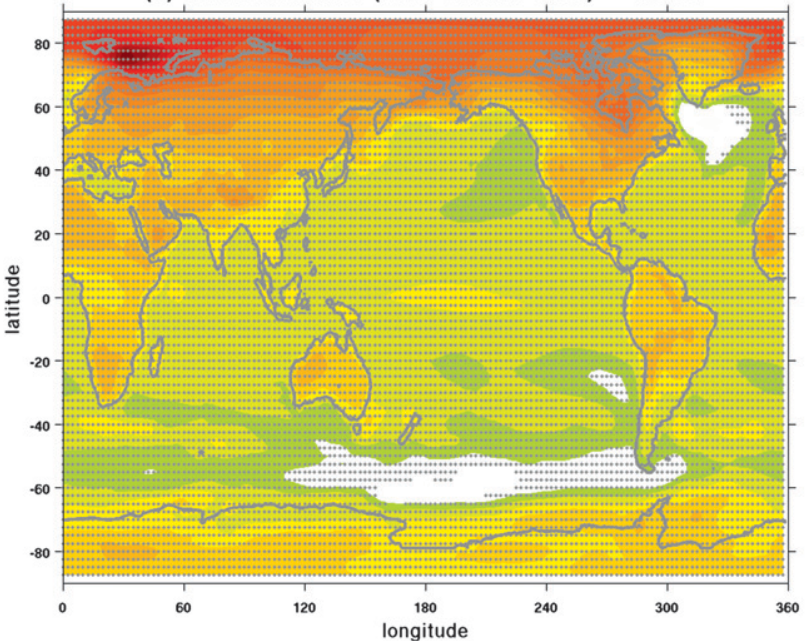

(b) TS Anomalies (GHG2025-REF1960) $1.31 \mathrm{~K}$

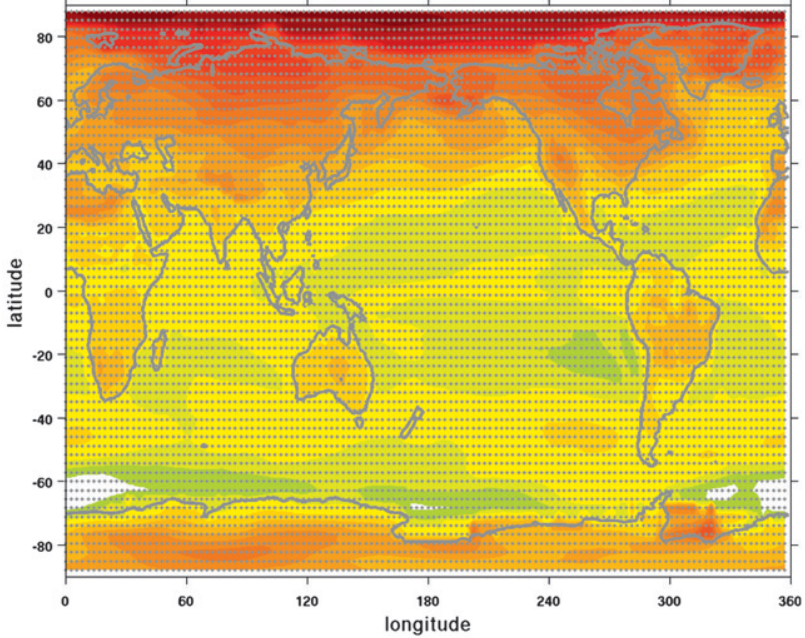

(d) TS Anomalies (CMIP5 2025-1960) $1.11 \mathrm{~K}$

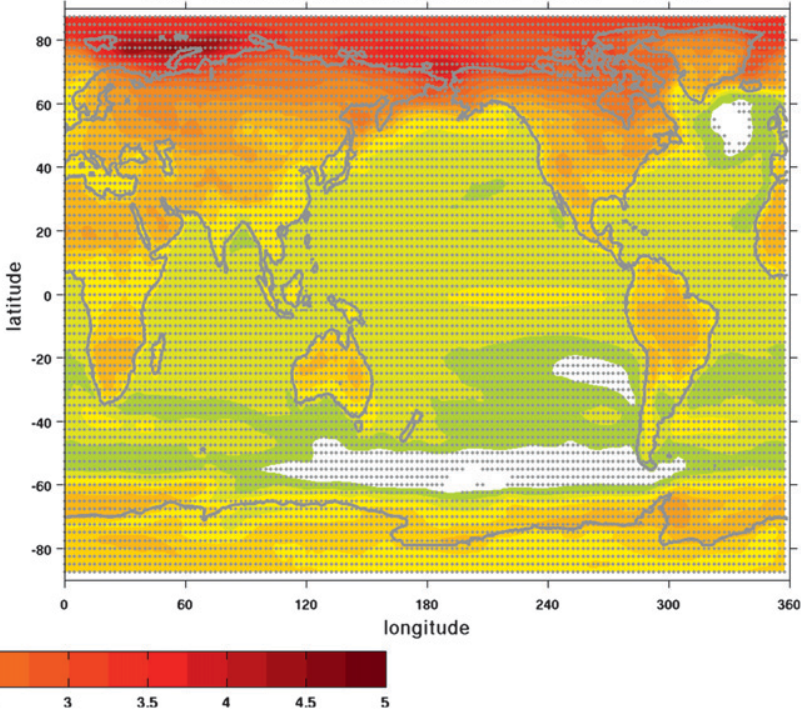

FIG. 3. Annual mean response in surface temperature (TS; in K) for the (a) WA and (b) increased GHG scenarios, during 2020-29, (c) the CMIP3 multimodel averages for A1B 2020-29 minus 20C3M 1955-64, and (d) the CMIP5 multimodel averages for RCP45 2020-29 minus historical 1955-64. The numbers shown in the title indicate the increase in globally averaged surface temperature [i.e., 0.84, 1.31, 1.08 , and $1.11 \mathrm{~K}$ for (a)-(d), respectively]. Dots indicate the $95 \%$ statistical significance.

ozone depletion and increases in CFC concentrations. In addition, we compute the changes in the hydrological cycle caused thermodynamically by changes in specific humidity and dynamically by changes in mean meridional circulation and by changes in transient eddy moisture transport.

\section{Understanding hydroclimate changes in the world avoided}

\section{a. Individual contributions from stratospheric ozone and $\mathrm{CFCs}$}

In this section, we seek to isolate the effects of stratospheric ozone depletion and CFC increase in the
WA scenario, and to determine their respective contributions. To accomplish this, we make use of the OZONE2025 and CFC2025 experiments, in which we independently specify the stratospheric ozone loss and $\mathrm{CFC}$ increase. Figure 7 shows the zonal mean equilibrium temperature response in the OZONE2025 and CFC2025 experiments, respectively. As expected, the stratospheric ozone loss leads to large cooling in the stratosphere but little change in tropospheric temperature; in contrast, the increase of CFCs warms up the middle and upper troposphere in the tropics and the subtropics, as well as the low levels in the $\mathrm{NH}$ polar regions. 
(a) P-E Anomalies (WA2025-REF1960)

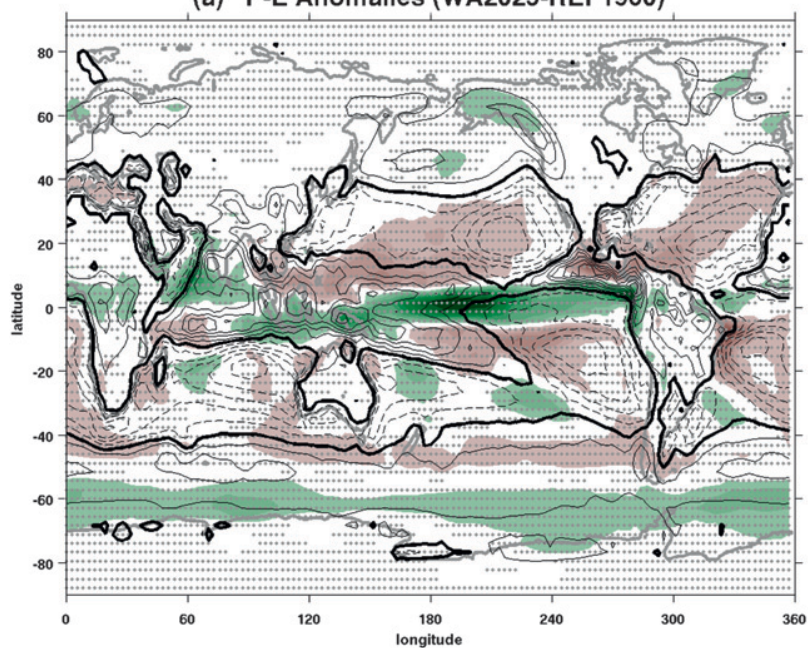

(c) P-E Anomalies (CMIP3 2025-1960)

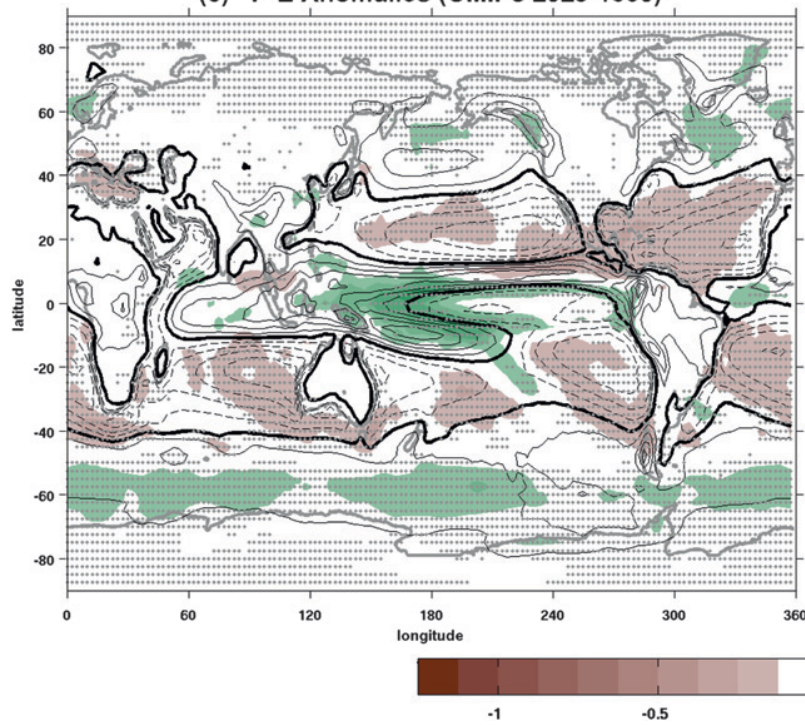

(b) P-E Anomalies (GHG2025-REF1960)

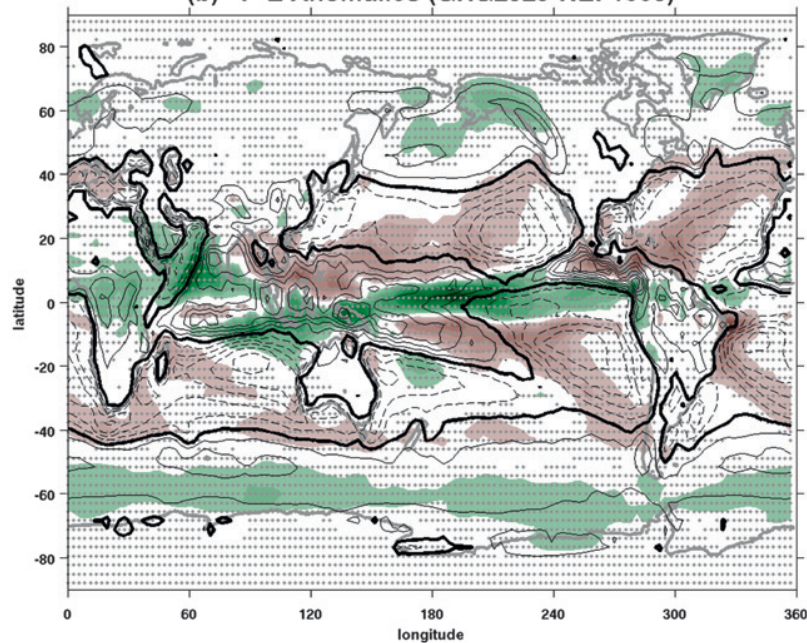

(d) P-E Anomalies (CMIP5 2025-1960)

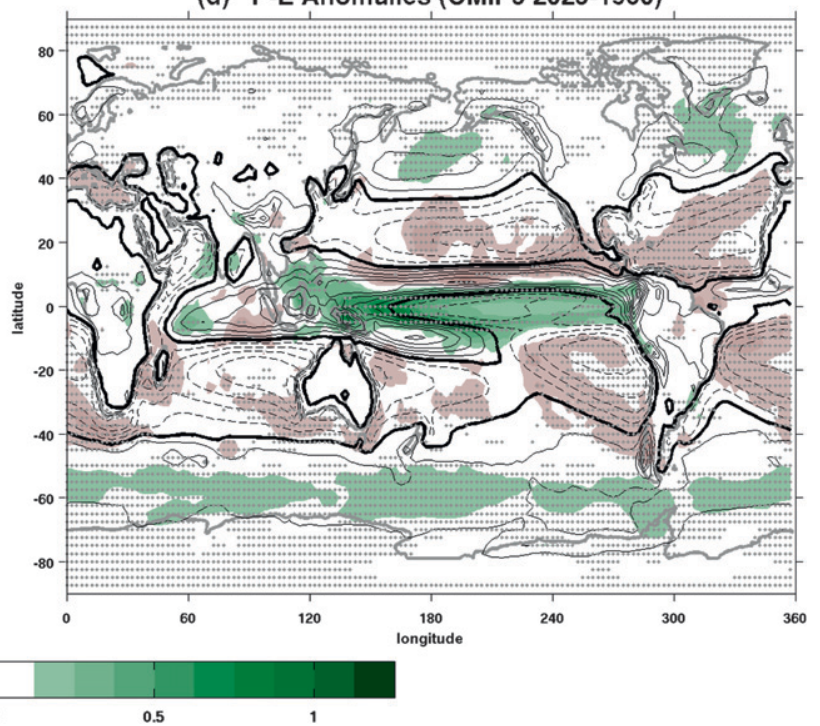

FIG. 4. As in Fig. 3, but for $P-E$. The climatologies are shown in contours with intervals of $1 \mathrm{~mm} \mathrm{day}^{-1}$ (solid contours: positive values, dashed contours: negative values, thick contours: zero values). The anomalies are shown in color shadings ( $\mathrm{mm} \mathrm{day}^{-1}$ ). Dots indicate the $95 \%$ statistical significance.

Figure 8 shows the zonal mean equilibrium $P-E$ response from the WA2025, OZONE2025, and CFC2025 experiments with circles indicating statistical significance. The sum of the OZONE2025 and CFC2025 responses is shown in thick gray line, and is close to the WA2025 response in most regions: this suggests that the hydrological cycle response to the individual forcings is largely linearly additive. As shown in Fig. 8, the zonal mean $P-E$ response in the WA scenario is mostly due to the increase of CFCs, especially in the tropics and the $\mathrm{NH}$. The $P-E$ response in the CFC2025 case is a typical global warming response: an enhanced moistening near the equator, a strengthening and poleward expansion of the subtropical dry zone, and a middle- and high-latitude moistening (Seager et al. 2010). It is also hemispherically symmetric.

In contrast, the $P-E$ response in the OZONE2025 case is much stronger in the $\mathrm{SH}$ than in the $\mathrm{NH}$. In the $\mathrm{SH}$, a "tripolar" $P-E$ response is observed, plotted with a thick blue line, with a subtropical moistening between $40^{\circ}$ and $20^{\circ} \mathrm{S}$, a midlatitude drying between roughly $55^{\circ}$ and $40^{\circ} \mathrm{S}$, and a high-latitude moistening poleward of $55^{\circ} \mathrm{S}$. This pattern is similar to that found in Kang et al. (2011). Such a tripolar response is consistent with the poleward shift and intensification of the transient eddy momentum flux, as well as the change in 


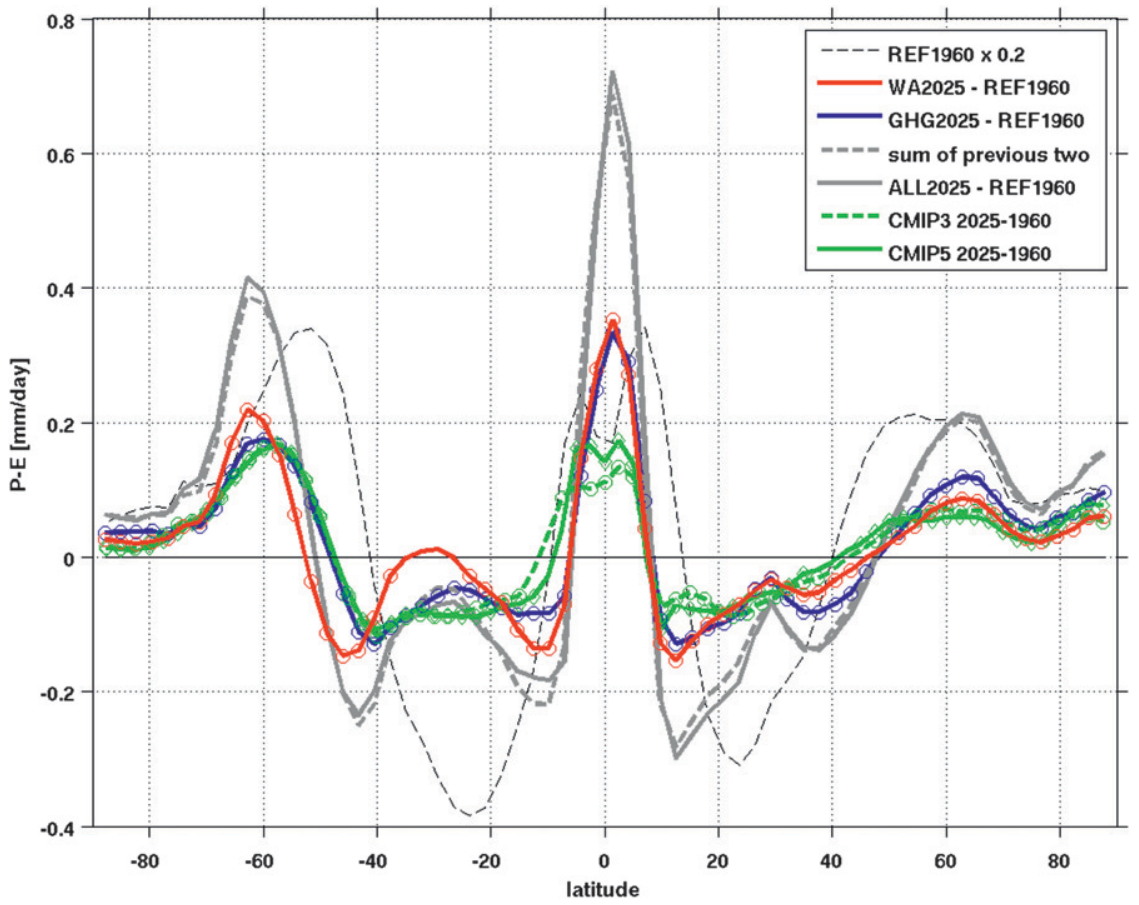

FIG. 5. The zonal and annual mean $P-E$ response for the WA2025, GHG2025, sum of the previous two experiments, and ALL2025. Also shown are the CMIP3 and CMIP5 multimodel average differences for 2020-29 minus 1955-64, as indicated in legend. For the REF1960 experiment, the values are divided by a factor of 5 . Circles indicate the $95 \%$ statistical significance for the responses in WA2025, GHG2025, and CMIP3 while diamond symbols are used for CMIP5.

vertical velocity in this scenario (shown in Figs. 9c,g). The anomalous convergence of transient eddy momentum flux roughly equatorward of $30^{\circ} \mathrm{S}$ drives a northward flow, and a southward flow poleward of $30^{\circ} \mathrm{S}$, inducing an anomalous rising motion and enhanced precipitation in the $\mathrm{SH}$ subtropics around $30^{\circ} \mathrm{S}$. Similarly, in the midlatitudes, a descending anomaly and reduced precipitation is seen around $45^{\circ} \mathrm{S}$ associated with an anomalous convergence of transient eddy momentum flux to the south and a divergence anomaly to the north. In the NH, in OZONE2025, the zonal mean hydrological cycle shifts poleward with a drying trend in the subtropics and a moistening trend in the middle and high latitudes, again consistent with the increase of transient eddy momentum flux, especially on the poleward flank, and the anomalous subsidence in the midlatitudes (shown in Figs. 9c,g).

Therefore, in addition to the increase in CFCs and resulting global warming effect, the stratospheric ozone depletion further increases the moistening trend in the SH high latitudes and, to a lesser extent, the subtropical drying trend and middle- and high-latitude moistening trend in the NH. It is also noted that, in the SH subtropics, there is a degree of cancellation between the drying trend due to CFC increase and the wetting trend due to stratospheric ozone depletion, leading to small changes in these regions.

\section{b. Thermodynamic and dynamic contributions}

To better understand the dynamical mechanisms underlying the changes in zonal mean hydrological cycle, we now examine the zonal mean atmospheric moisture budget for the WA2025 scenario, as well as for the OZONE2025 and CFC2025 experiments. The analysis follows the one used in Seager et al. (2010) and Seager and Naik (2012), and consists of breaking down the zonal mean changes in $P-E$ into those due to changes in specific humidity (the thermodynamic component, $\mathrm{TH})$, mean circulation dynamics (MCD), and transient eddy moisture flux convergence (TE):

$$
\begin{aligned}
\delta\langle\bar{P}-\bar{E}\rangle & \approx \delta \mathrm{TH}+\delta \mathrm{MCD}+\delta \mathrm{TE}, \\
\delta \mathrm{TH} & =-\frac{1}{a g \rho_{w}} \int_{0}^{p_{s}} \frac{1}{\cos \phi} \frac{\partial}{\partial \phi}\langle\bar{v} \cdot \delta \bar{q}\rangle \cos \phi d p, \\
\delta \mathrm{MCD} & =-\frac{1}{a g \rho_{w}} \int_{0}^{p_{s}} \frac{1}{\cos \phi} \frac{\partial}{\partial \phi}\langle\delta \bar{v} \cdot \bar{q}\rangle \cos \phi d p,
\end{aligned}
$$


WA2025-REF1960

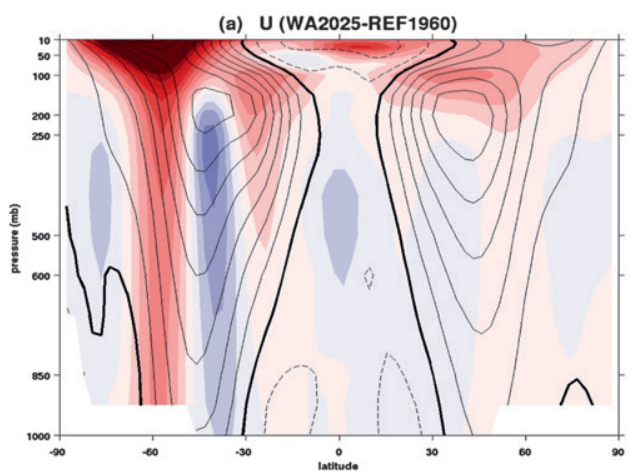

(c) U'v' (WA2025-REF1960)
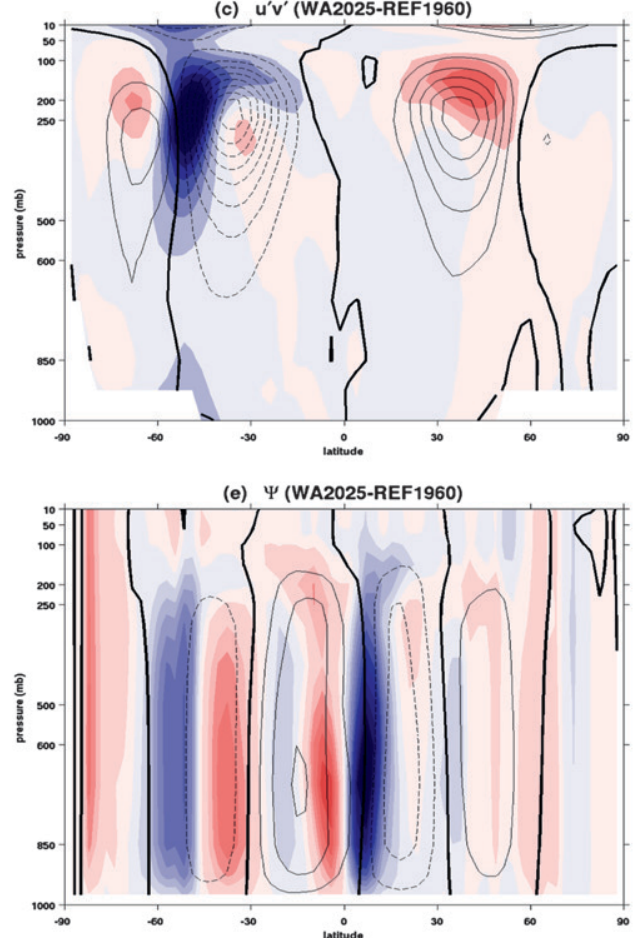

(g) $\omega$ (WA2025-REF1960)

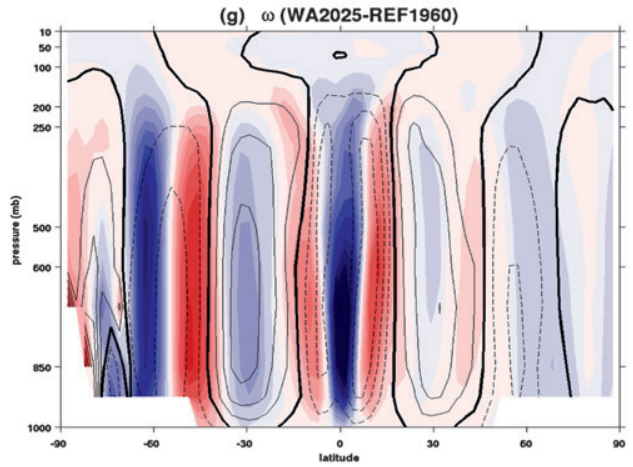

GHG2025-REF1960
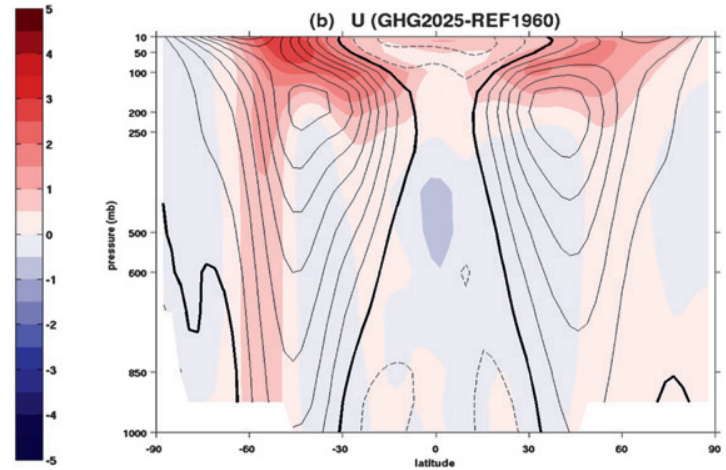

(d) U'v' (GHG2025-REF1960)
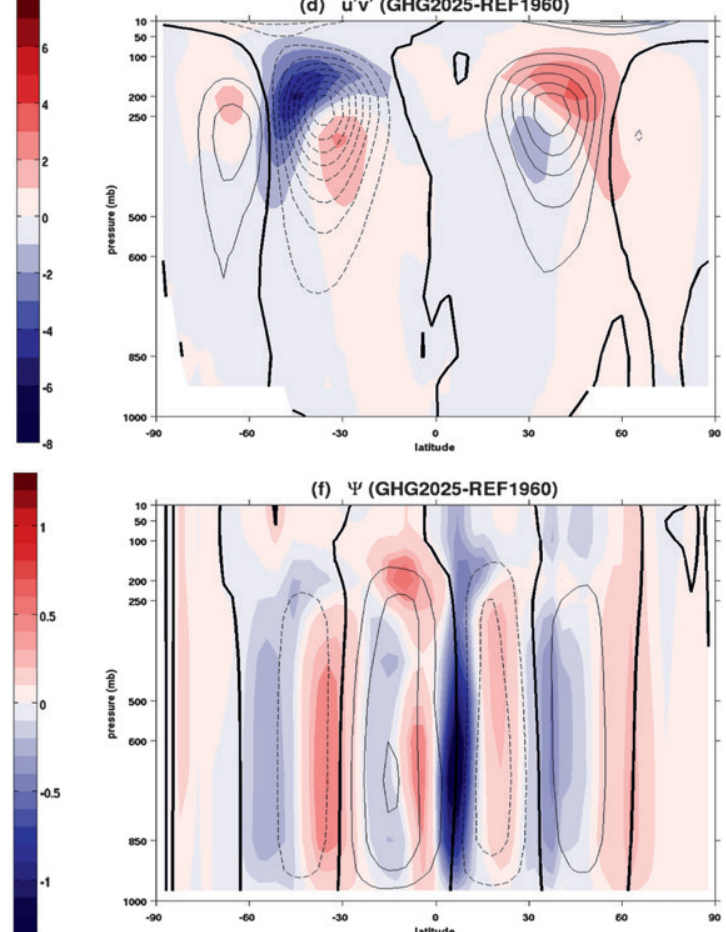

(h) $\omega$ (GHG2025-REF1960)

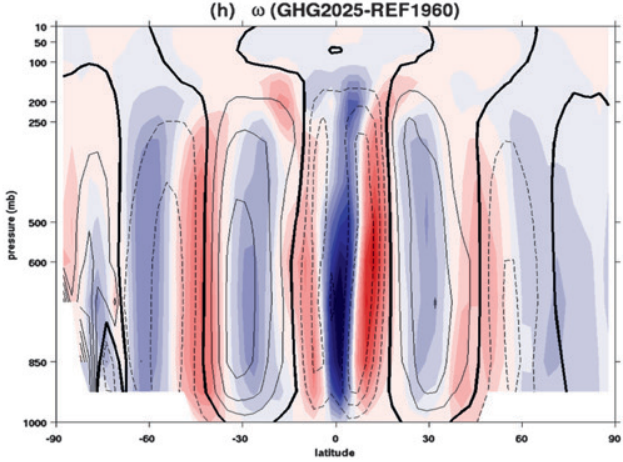

FIG. 6. Annual mean equilibrium response in (a),(b) zonal mean zonal wind, (c),(d) transient eddy momentum flux, (e),(f) Eulerian mean streamfunction, and (g),(h) vertical velocity for the (left) WA and (right) increased GHG scenarios, respectively, during 2020-29. Black contours show the climatologies and color shadings show the anomalies. Negative (positive) values in $\omega$ indicate upward (downward) motion. The contour intervals are $5 \mathrm{~m} \mathrm{~s}^{-1}$ for (a) and (b), $10 \mathrm{~m}^{2} \mathrm{~s}^{-2}$ for (c) and (d), $5 \times 10^{9} \mathrm{~kg} \mathrm{~s}^{-1}$ for (e) and (f), and $5 \mathrm{mb} \mathrm{day}^{-1}$ for (g) and (h). 
(a) T anomalies (OZONE2025-REF1960)

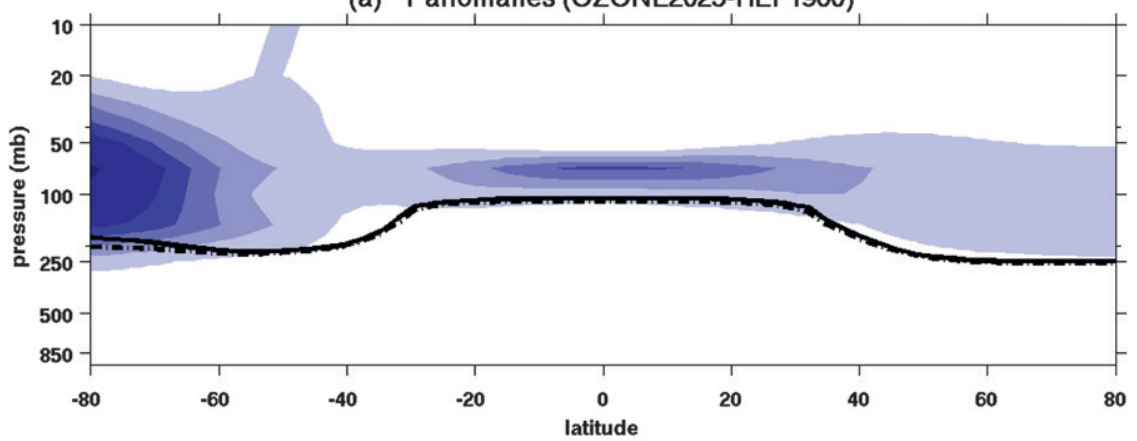

(b) T anomalies (CFC2025-REF1960)

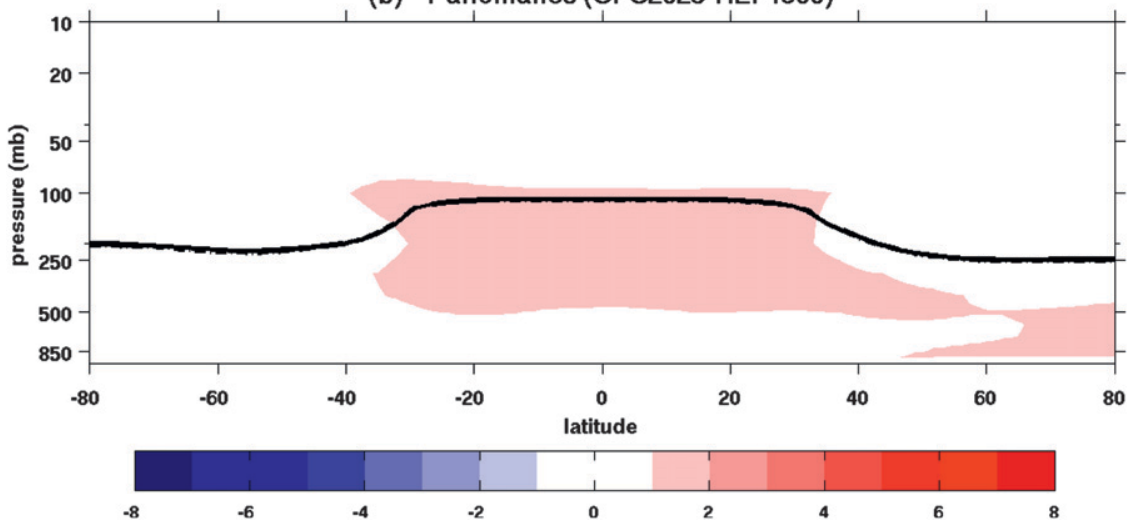

FIG. 7. As in Fig. 1, but for the (a) OZONE2025 and (b) CFC2025 experiments.

$$
\delta \mathrm{TE}=-\frac{1}{a g \rho_{w}} \int_{0}^{p_{s}} \frac{1}{\cos \phi} \frac{\partial}{\partial \phi} \delta\left\langle\overline{v^{\prime} q^{\prime}}\right\rangle \cos \phi d p
$$

where $g$ is the gravitational acceleration, $\rho_{w}$ is the density of water, $p_{s}$ is the surface pressure, $a$ is Earth's radius, $v$ is the meridional velocity, and $q$ is the specific humidity. Here again overbars indicate monthly means, primes indicate departures from monthly means, and angle brackets denote zonal averages. In Eq. (1), both nonlinear terms and changes in the surface term (see Seager and Naik 2012) are assumed to be small and have thus been neglected.

Figures $10 \mathrm{a}-\mathrm{c}$ show the thermodynamic and dynamic attributions for the OZONE2025, CFC2025 and WA2025 experiments, respectively. The sum of the thermodynamic, mean circulation, and transient eddy components is plotted with a thick gray line and is in general close to the zonal mean $P-E$ response for all the three scenarios. ${ }^{4}$ Consider first the OZONE2025 experiment,

\footnotetext{
${ }^{4}$ Some disagreement is expected because the calculation is performed diagnostically on pressure coordinate rather than on hybrid sigma/pressure coordinates and using different numerical methods than those in the actual model. Discrepancies may also come from the neglect of any model moisture diffusion.
}

shown in Fig. 10a. As a result of stratospheric ozone depletion, the thermodynamic contribution is close to zero everywhere across the globe: this is different from a typical global warming response, but is expected in that ozone depletion does not cause an appreciable change in tropospheric surface temperatures (shown in Fig. A2 in the appendix; Solomon et al. 2007). On the other hand, the dynamics are important: the changes in both the mean meridional circulation and transient eddy moisture flux convergence caused by ozone depletion contribute to the hydrological cycle change in the subtropics and middle and high latitudes in both hemispheres. In addition to the change in mean meridional circulation in the extratropics, which is presumably driven by transient eddy momentum flux anomalies, the transient eddy moisture flux also intensifies in the middle and high latitudes and transports more moisture poleward.

Consider next the CFC2025 experiment, shown in Fig. 10b. This case looks like a typical global warming scenario, with both the $P-E$ response and its attributions largely consistent with Fig. 12 (top) of Seager et al. (2010), which shows the global warming results for a CMIP3 multimodel average. The thermodynamic contribution is primarily an intensification of the climatological 


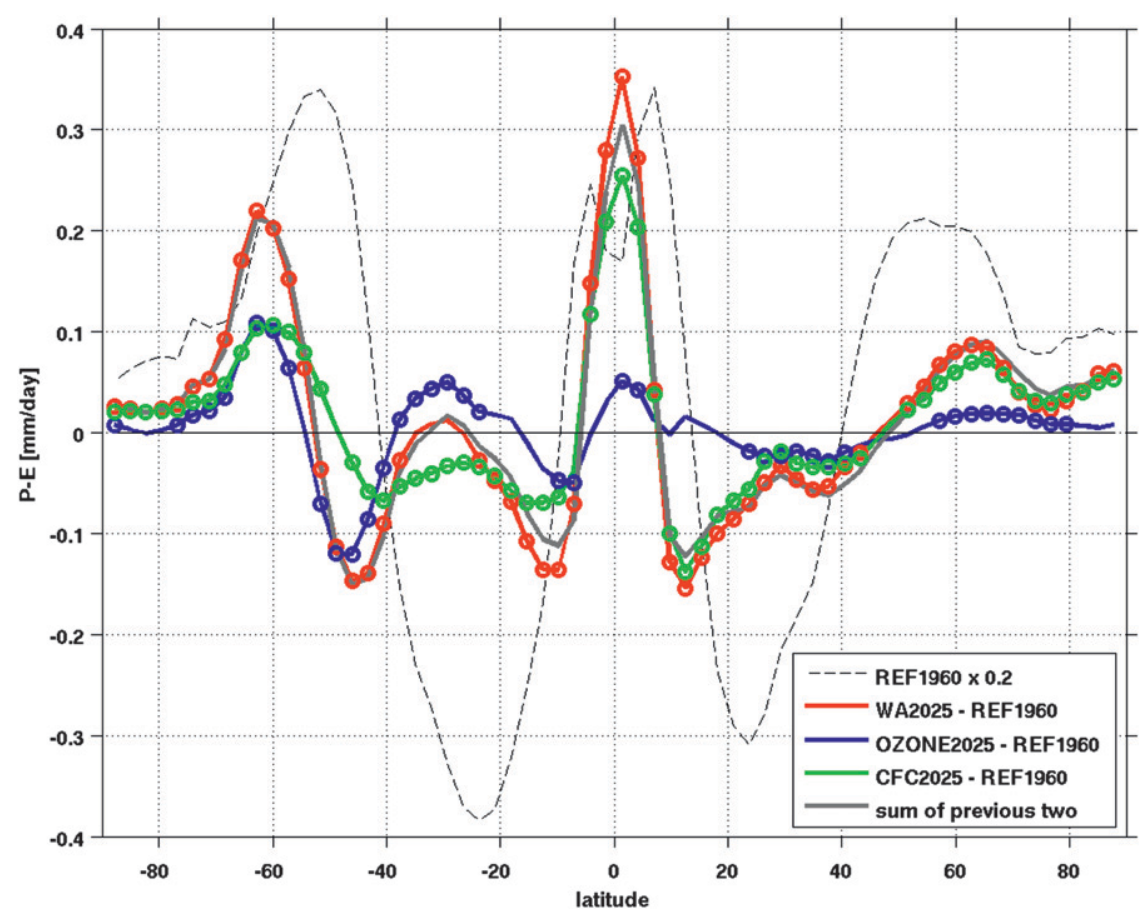

FIG. 8. The zonal and annual mean $P-E$ anomalies from the WA2025, OZONE2025, and CFC2025 experiments, as well as the sum of the former two (i.e., the responses in OZONE2025 and in CFC2025), as indicated in the legend. Also shown is the REF1960 experiment with the $P-E$ climatologies divided by a factor of 5 . Circles indicate the $95 \%$ statistical significance. Note that the $y$ axis goes from -0.4 to $0.4 \mathrm{~mm}^{\text {day }}{ }^{-1}$.

hydrological cycle (i.e., wet gets wetter and dry gets drier) but itself does not suggest any broadening of the subtropical dry zones. The contribution from the mean meridional circulation shows a tripolar response in each hemisphere away from the tropics (i.e., a moistening trend roughly poleward of $60^{\circ}$, a drying trend between $60^{\circ}$ and $40^{\circ}$, and a moistening trend in the subtropics between $40^{\circ}$ and $20^{\circ}$ ). This is consistent with the change in transient eddy momentum flux and vertical velocity (shown in Figs. 9d,h). The transient eddy momentum flux shifts poleward in both hemispheres and drives anomalous rising motions in the subtropics and high latitudes, leading to a moistening trend in these regions, and vice versa for the drying trend in the midlatitudes. This is indeed similar to the tripolar response seen in the ozone-loss scenario in the $\mathrm{SH}$ (shown in Fig. 10a). In fact, it is largely the eddy-driven mean meridional circulation change that contributes to the poleward expansion of the subtropical dry zone. However, in total the subtropics get drier and the middle and high latitudes get wetter because of the dominant effect of the thermodynamics. The mean meridional circulation also significantly increases the $P-E$ near the equator, which is consistent with an upward vertical velocity anomaly (the latter can be seen in Fig. 9h). The transient eddy moisture flux also significantly intensifies and transfers more moisture from the subtropics to the middle and high latitudes in both hemispheres, contributing to drying the former and wetting the latter.

Figure 10c shows the thermodynamic and dynamic contributions for the total WA scenario. The enhanced moistening near the equator is largely due to the mean meridional circulation change as a result of CFC increase, and the resulting intensified rising motion. The thermodynamic component, as a result of CFC increase, dominates the mean circulation contribution in the $\mathrm{NH}$ and causes enhanced subtropical drying and midlatitude moistening. The transient eddies also help transport more moisture from the subtropics to the midlatitudes. In the $\mathrm{SH}$, both the changes in the mean meridional circulation and transient eddy moisture flux, as a result of both stratospheric ozone depletion and CFC increase, contribute to the midlatitude drying trend and high-latitude moistening trend. Note how the mean circulation and thermodynamic components largely offset each other in the SH subtropics, resulting in small hydrological cycle changes.

\section{Discussion and conclusions}

In summary then, we have calculated the response of the hydroclimate and the atmospheric zonal mean 


\section{OZONE2025-REF1960}
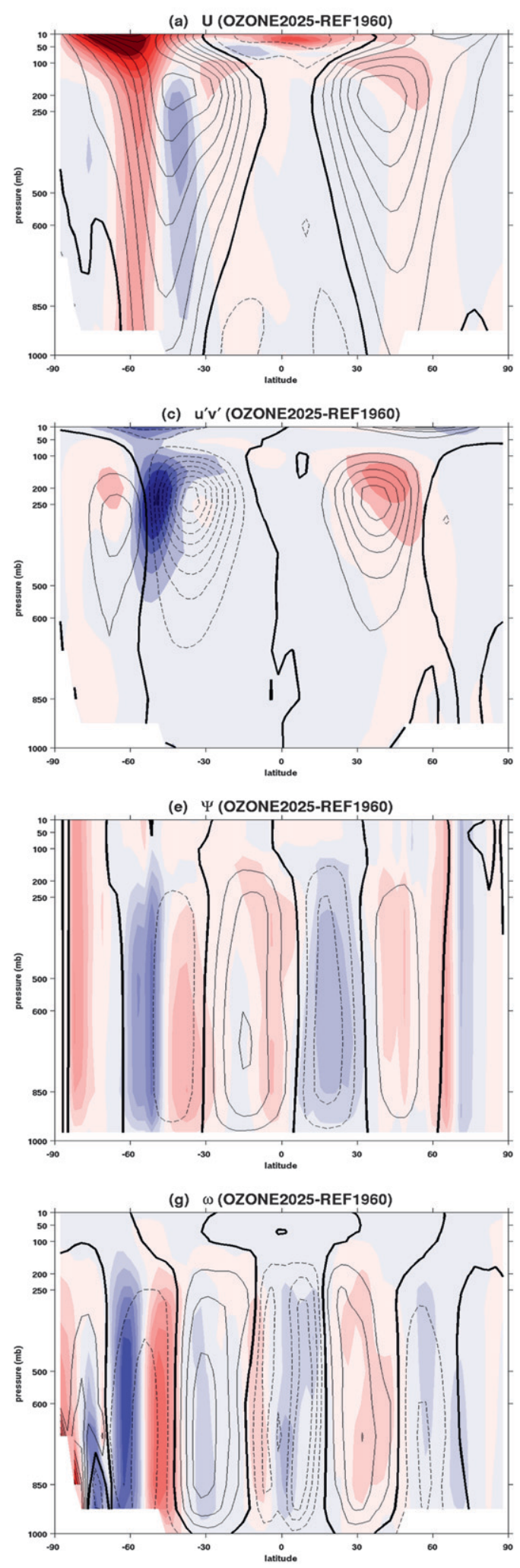
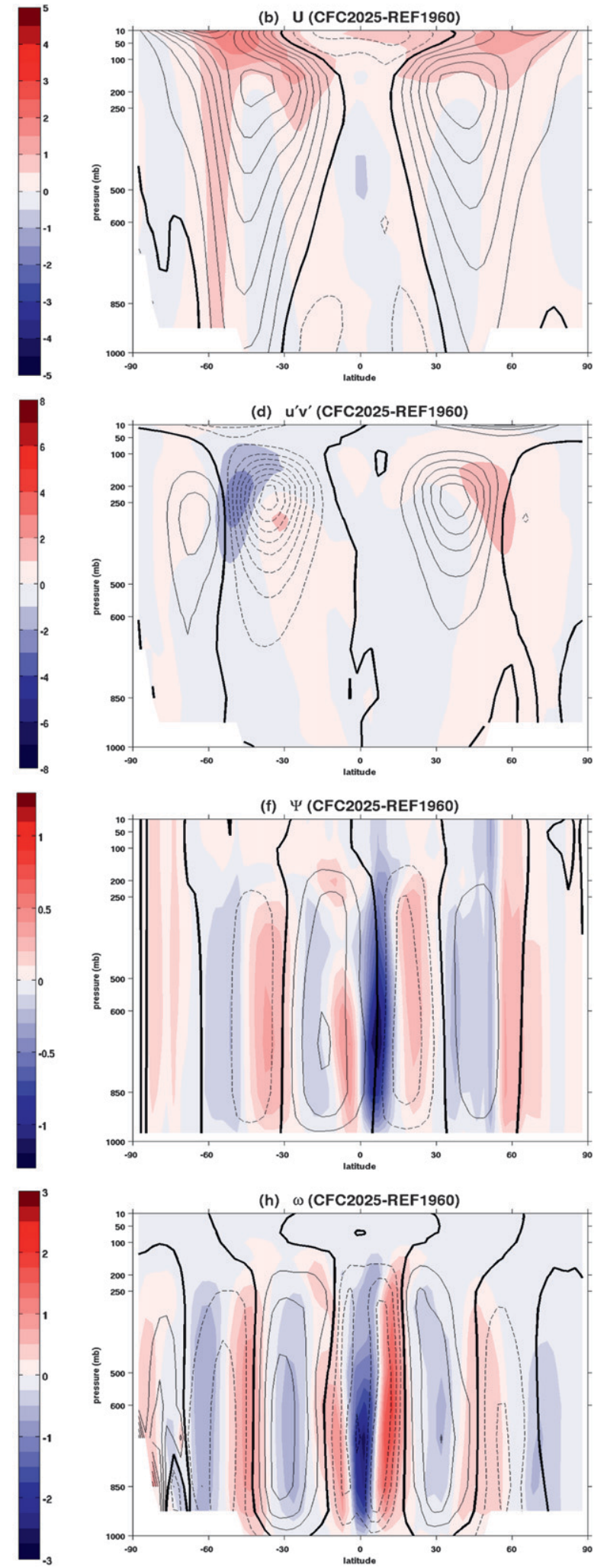

\section{CFC2025-REF1960}

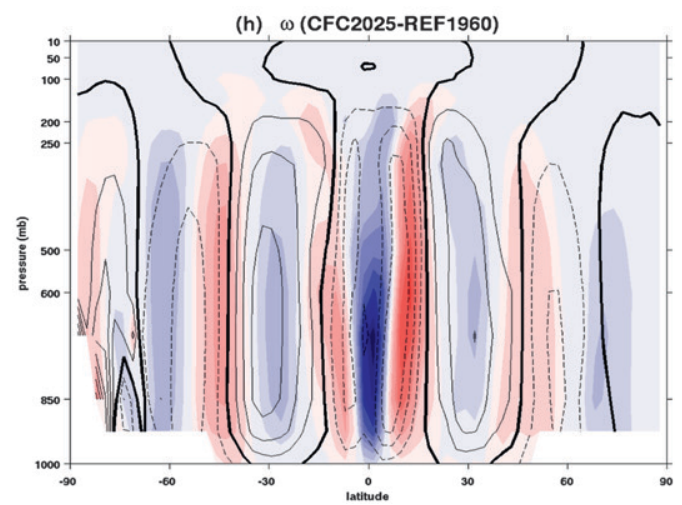

FIG. 9. As in Fig. 6, but for the (left) OZONE2025 and (right) CFC2025 experiments. 
(a) OZONE2025 - REF1960

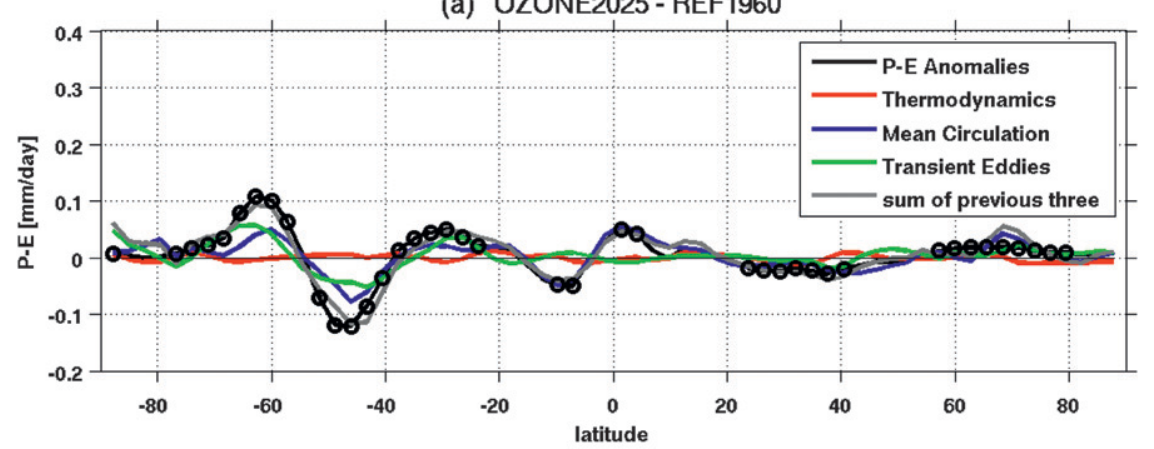

(b) CFC2025 - REF1960

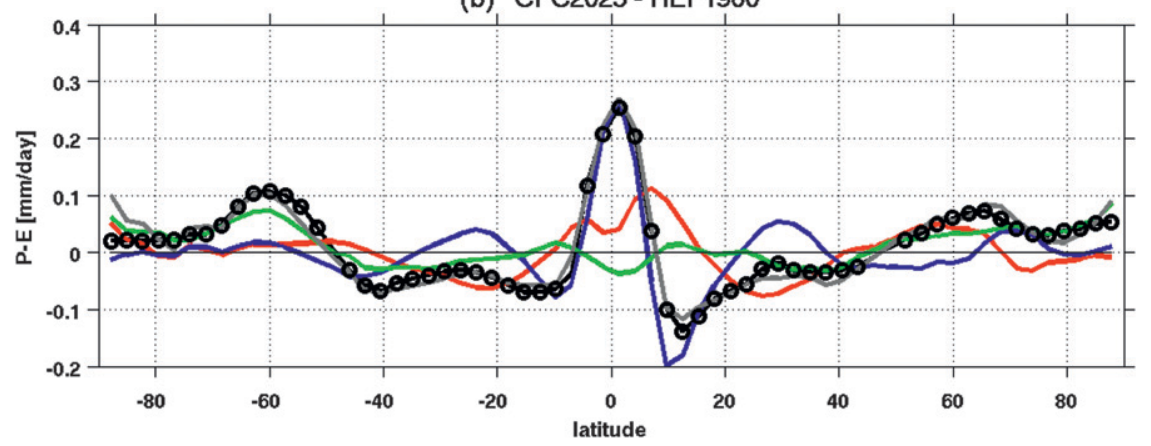

(c) WA2025 - REF1960

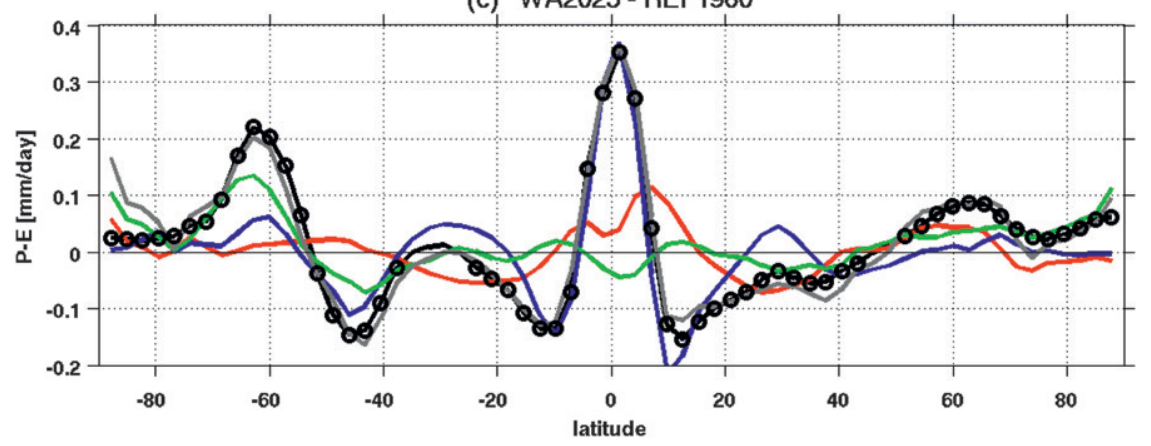

FIG. 10. The zonal and annual mean $P-E$ anomalies and their decomposition into the thermodynamics (TH), meridional circulation dynamics (MCD), and transient eddy (TE) components as well as the sum of the three, as indicated in legend, for the (a) OZONE2025, (b) CFC2025, and (c) WA2025 experiments.

circulation in the coming decade under the "world avoided" (WA) scenario, which would presumably have occurred had the Montreal Protocol not gone into effect. We find that during 2020-29, severe ozone loss and large CFC increases-had they occurred-would have been capable of seriously affecting the hydrological cycle and the atmospheric zonal mean circulation across the entire planet. From the time-slice experiments presented here, the WA response in $P-E$ shows a "dry gets drier and wet gets wetter" pattern in both hemispheres, similar to the one associated with global warming. Specifically, $P-E$ increases near the equator, and the tropical rainbands narrow in both hemispheres. The subtropical dry regions in general become drier, especially in the
$\mathrm{NH}$, and expand farther poleward. In the middle and high latitudes increased moistening is found poleward of $50^{\circ} \mathrm{N} / \mathrm{S}$ and drying equatorward, resulting in a poleward shift of the midlatitude precipitation zones.

Strikingly the equilibrium changes in $P-E$ under the WA scenario are of a magnitude comparable to those in the increased GHG scenario over identical periods and using the same model configuration. More importantly, they are also similar in both pattern and magnitude to the transient CMIP3 and CMIP5 climate change projections during 2020-29. This suggests that without the Montreal Protocol, ozone loss and CFC increases would have significantly affected the global hydroclimate in the coming decade, amplifying the effect due to GHG increase alone. 
Furthermore, by independently specifying the ozone loss and CFC increase in model integrations, we have shown that both contribute substantially to the hydrological cycle change in the WA scenario. In the tropics and the $\mathrm{NH}$, the hydrological cycle changes are largely attributed to CFC increase, which gives rise to enhanced moistening near the equator and in the middle and high latitudes and increased drying in the subtropics. Both stratospheric ozone depletion and $\mathrm{CFC}$ increase contribute to the poleward shift and intensification of the $\mathrm{SH}$ midlatitude wet regions. In the SH subtropics, there is a large degree of compensation between the drying trend due to CFC increase and the wetting trend due to ozone depletion.

The dynamical mechanisms underlying the hydroclimate changes in the WA scenario were further explored by analyzing the zonal mean moisture budget and its decomposition into the thermodynamic, mean circulation dynamic and transient eddy moisture flux components. In the WA scenario, the enhanced moistening near the equator is primarily due to the change in mean meridional circulation that follows from the CFC increase and a maximum sea surface temperature warming at the equator. The thermodynamic and transient eddy moisture flux components lead to a strengthening of the subtropical drying and middle- and high-latitude moistening in the $\mathrm{NH}$, and are primarily the result of the CFC increase. In addition, both the mean meridional circulation and transient eddy moisture flux components contribute to the poleward displacement and intensification of the midlatitude wet regions in the $\mathrm{SH}$, and are the result of both stratospheric ozone loss and CFC increase. In the SH subtropics, the contributions from the mean meridional circulation change (due to both stratospheric ozone loss and CFC increase) and the thermodynamic change (as a result of CFC increase) largely compensate, causing little change in the hydrological cycle.

One caveat of this study is that although CAM3 is an IPCC AR4-class AGCM, it has a poor representation of the stratosphere (e.g., Sassi et al. 2010; Wu et al. 2013) and is coupled to a slab ocean model and a thermodynamic sea ice model in this study. Therefore, analysis of the WA hydroclimate changes using a model with a wellresolved stratosphere and with fully coupled deep ocean, sea ice, and chemistry would be useful, and will be investigated in the future.

The goal of this paper has been to determine the hydroclimate change that would have occurred had CFCs not been regulated. A policy-relevant analysis of the climate impacts due to the implementation of the Montreal Protocol would need to also account for the greenhouse warming effects associated with the replacement refrigerants, such as the hydrofluorocarbons
(HFCs). The HFCs do not destroy stratospheric ozone but have high global warming potential, and are thus among the GHGs regulated by the Kyoto Protocol. In the absence of new controls, the HFCs used as ODS substitutes might grow rapidly in the future and their contribution to climate change is "an unintended negative side effect of the Montreal Protocol" (Velders et al. 2012). However, the radiative forcing due to the HFC increase is less than $0.1 \mathrm{~W} \mathrm{~m}^{-2}$ during 2020-29, considerably smaller than that of the CFCs in the WA scenario (see Fig. 3 in Velders et al. 2007), and therefore HFCs were not considered in this study.

It is only in recent years that the importance of changes in stratospheric temperature and circulation for surface circulation, climate, and the hydrological cycle has become widely appreciated. As such, the full impact of increased CFCs-and the accompanying stratospheric ozone loss-on Earth's physical, chemical, and biological systems was not fully appreciated when the Montreal Protocol regulated their phased withdrawal from use. The serious hydrological impacts of CFCs and ozone depletion shown here, with important implications for water resources, drought and flood risk, and ecosystems, were avoided unintentionally. It is worth noting that, as other human activities continue to perturb our planet, we may not always be so lucky.

Acknowledgments. The authors appreciate the useful comments of three anonymous reviewers. The authors are grateful to Drs. P. A. Newman and L. Oman for providing the halogens, GHGs, and ozone field datasets from the "World Avoided" integrations. We also would like to thank Drs. Mingfang Ting, Tiffany A. Shaw, Karen Smith, Jason Smerdon and Arlene Fiore, and the Global Decadal Hydroclimate $(\mathrm{GloDecH})$ group at Lamont-Doherty Earth Observatory and Columbia University for their helpful comments and advice. We also appreciate discussions with Drs. Sarah Kang and Olivier Pauluis. We acknowledge the World Climate Research Programme's Working Group on Coupled Modelling, which is responsible for CMIP, and we thank the climate modeling groups for producing and making available their model output. For CMIP the U.S. Department of Energy's Program for Climate Model Diagnosis and Intercomparison provides coordinating support and led development of software infrastructure in partnership with the Global Organization for Earth System Science Portals. RS is supported by the Department of Energy (Award DE-SC0005107) and the National Oceanic and Atmospheric Administration (Awards NA08OAR4320912 and NA10OAR4320137). The work of LMP is funded, in part, by the U.S. National Science Foundation. 
(a) TOA Energy Budget (OZONE2025-REF1960)

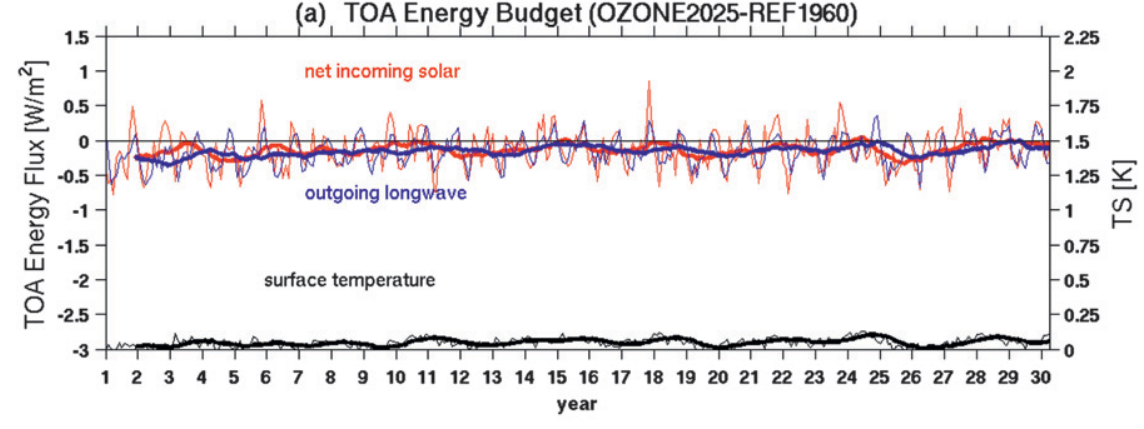

(b) TOA Energy Budget (CFC2025-REF1960)

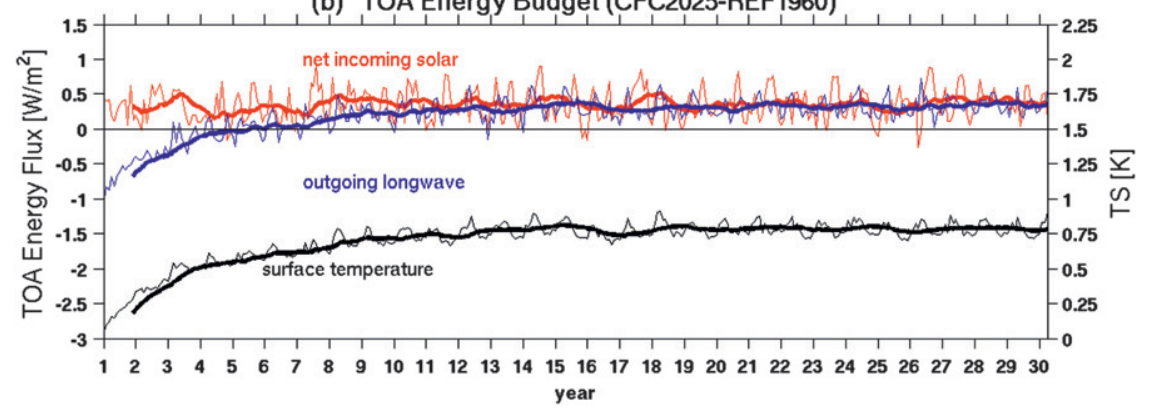

FIG. A1. As in Fig. 2, but for the (a) OZONE2025 and (b) CFC2025 experiments.

\section{APPENDIX}

\section{Top-of-the-Atmosphere Energy Flux Adjustment and Surface Temperature Response for the OZONE2025 and CFC2025 Experiments}

Figure A1 shows the adjustment of the net incoming solar radiation and outgoing longwave radiation (OLR) at the top of the atmosphere (TOA) for the stratospheric ozone depletion alone and CFC increase alone experiments. As a result of ozone loss, both the incoming solar radiation and OLR decrease in the global and annual average, and the radiation balance is reached rapidly. There is also little change in surface temperature due to stratospheric ozone depletion alone. The energy flux adjustment under the scenario of CFC increase behaves differently and is a typical global warming response. Immediately after the increase of CFCs, the OLR
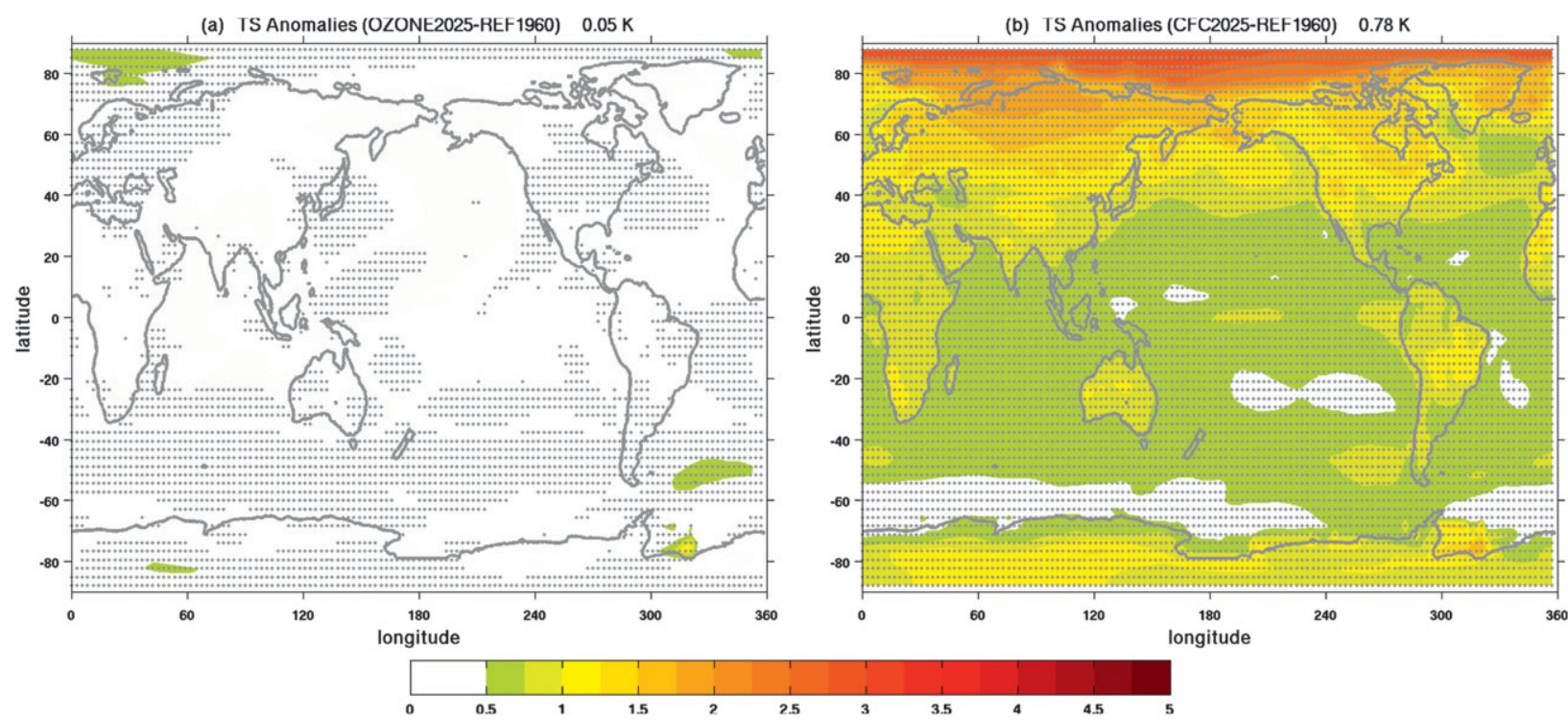

FIG. A2. As in Fig. 3, but for the (a) OZONE2025 and (b) CFC2025 experiments. 
decreases while the net incoming solar radiation increases, leading to an increase in surface temperature. As the surface temperature gradually increases, the OLR also increases until the radiative balance is finally reached.

Figure A2 shows the annual mean surface temperature (TS) response for the OZONE2025 and CFC2025 experiments, respectively. The TS increase in the WA scenario is largely due to CFC increase while stratospheric ozone loss contributes little to surface warming.

\section{REFERENCES}

Andrady, A., and Coauthors, 2012: Environmental effects of ozone depletion and its interactions with climate change: Progress report. Photochem. Photobiol. Sci., 11, 13-27.

Cionni, I., and Coauthors, 2011: Ozone database in support of CMIP5 simulations: Results and corresponding radiative forcing. Atmos. Chem. Phys., 11, 11 267-11 292, doi:10.5194/ acp-11-11267-2011.

Collins, W. D., and Coauthors, 2006: The formulation and atmospheric simulation of the Community Atmosphere Model version 3 (CAM3). J. Climate, 19, 2144-2161.

Egorova, T., E. Rozanov, J. Gröbner, M. Hauser, and W. Schmutz, 2012: Montreal Protocol benefits simulated with CCM SOCOL. Atmos. Chem. Phys. Discuss., 12, 17 001-17 030, doi:10.5194/ acpd-12-17001-2012.

Farman, J. C., B. G. Gardiner, and J. D. Shanklin, 1985: Large losses of total ozone in Antarctica reveal seasonal ClOx/NOx interaction. Nature, 315, 207-210, doi:10.1038/315207a0.

Garcia, R. R., D. E. Kinnison, and D. R. Marsh, 2012: "World avoided" simulations with the Whole Atmosphere Community Climate Model. J. Geophys. Res., 117, D23303, doi:10.1029/ 2012JD018430.

Held, I. M., and B. J. Soden, 2006: Robust responses of the hydrological cycle to global warming. J. Climate, 19, 5686-5699.

Kang, S., L. M. Polvani, J. C. Fyfe, and M. Sigmond, 2011: Impact of polar ozone depletion on subtropical precipitation. Science, 332, 951-954.

Mäder, J. A., J. Staehelin, T. Peter, D. Brunner, H. E. Rieder, and W. A. Stahel, 2010: Evidence for the effectiveness of the Montreal Protocol to protect the ozone layer. Atmos. Chem. Phys., 10, 12 161-12 171, doi:10.5194/acp-10-12161-2010.

McLandress, C., T. G. Shepherd, J. F. Scinocca, D. A. Plummer, M. Sigmond, A. I. Jonsson, and M. C. Reader, 2011: Separating the dynamical effects of climate change and ozone depletion. Part II: Southern Hemisphere troposphere. J. Climate, 24, 1850-1868.

Meehl, G. A., C. Covey, T. Delworth, M. Latif, B. McAvaney, J. F. B. Mitchell, R. J. Stouffer, and K. E. Taylor, 2007: The WCRP CMIP3 multimodel dataset: A new era in climate change research. Bull. Amer. Meteor. Soc., 88, 1383-1394.

Meinshausen, M., and Coauthors, 2011: The RCP greenhouse gas concentrations and their extension from 1765 to 2300 . Climatic Change, 109, 213-241, doi:10.1007/s10584-011-0156-z.

Molina, M. J., and F. S. Rowland, 1974: Stratospheric sink for chlorofluoromethanes: Chlorine atom-catalysed destruction of ozone. Nature, 249, 810-812, doi:10.1038/249810a0.

Montzka, S. A., J. H. Butler, J. W. Elkins, T. M. Thompson, A. D. Clarke, and L. T. Lock, 1999: Present and future trends in the atmospheric burden of ozone-depleting halogens. Nature, 398, 690-694, doi:10.1038/19499.
Morgenstern, O., P. Braesicke, M. M. Hurwitz, F. M. O'Connor, A. C. Bushell, C. E. Johnson, and J. A. Pyle, 2008: The world avoided by the Montreal Protocol. Geophys. Res. Lett., 35, L16811, doi:10.1029/2008GL034590.

Nakicenovic, N., and R. Swart, Eds., 2000: Special Report on Emissions Scenarios. Cambridge University Press, 612 pp.

Newchurch, M. J., E.-S. Yang, D. M. Cunnold, G. C. Reinsel, J. M. Zawodny, and I. J. M. Russell, 2003: Evidence for slowdown in stratospheric ozone loss: First stage of ozone recovery. J. Geophys. Res., 108, 4507, doi:10.1029/2003JD003471.

Newman, P. A., and Coauthors, 2009: What would have happened to the ozone layer if chlorofluorocarbons (CFCs) had not been regulated? Atmos. Chem. Phys., 9, 2113-2128, doi:10.5194/ acp-9-2113-2009.

Perlwitz, J., S. Pawson, R. L. Fogt, J. E. Nielsen, and W. D. Neff, 2008: Impact of stratospheric ozone hole recovery on Antarctic climate. Geophys. Res. Lett., 35, L08714, doi:10.1029/ 2008GL033317.

Polvani, L. M., M. Previdi, and C. Deser, 2011a: Large cancellation, due to ozone recovery, of future Southern Hemisphere atmospheric circulation trends. Geophys. Res. Lett., 38, L04707, doi:10.1029/2011GL046712.

D. W. Waugh, G. J. P. Correa, and S.-W. Son, 2011b: Stratospheric ozone depletion: The main driver of twentiethcentury atmospheric circulation changes in the Southern Hemisphere. J. Climate, 24, 795-812.

Reichler, T., and J. Kim, 2008: How well do coupled models simulate today's climate? Bull. Amer. Meteor. Soc., 89, 303-311.

Reinsel, G. C., E. Weatherhead, G. C. Tiao, A. J. Miller, R. M. Nagatani, D. J. Wuebbles, and L. E. Flynn, 2002: On detection of turnaround and recovery in trend for ozone. J. Geophys. Res., 107, 4078, doi:10.1029/2001JD000500.

—, A. J. Miller, E. C. Weatherhead, L. E. Flynn, R. M. Nagatani, G. C. Tiao, and D. J. Wuebbles, 2005: Trend analysis of total ozone data for turnaround and dynamical contributions. J. Geophys. Res., 110, D16306, doi:10.1029/2004JD004662.

Salby, M. L., E. A. Titova, and L. Deschamps, 2011: Rebound of Antarctic ozone. Geophys. Res. Lett., 38, L09702, doi:10.1029/ 2011 GL047266.

- — - and - 2012: Changes of the Antarctic ozone hole: Controlling mechanisms, seasonal predictability, and evolution. J. Geophys. Res., 117, D10111, doi:10.1029/2011JD016285.

Sassi, F., R. R. Garcia, D. Marsh, and K. W. Hoppel, 2010: The role of the middle atmosphere in simulations of the troposphere during Northern Hemisphere winter: Differences between high- and low-top models. J. Atmos. Sci., 67, 3048-3064.

Seager, R., and N. Naik, 2012: A mechanisms-based approach for detecting recent anthropogenic hydroclimate change. J. Climate, 25, 236-261.

, and Coauthors, 2007: Model projections of an imminent transition to a more arid climate in southwestern North America. Science, 316, 1181-1184.

— N. N. Naik, and G. A. Vecchi, 2010: Thermodynamic and dynamic mechanisms for large-scale changes in the hydrological cycle in response to global warming. J. Climate, 23, 4651-4668.

Solomon, S., D. Qin, M. Manning, Z. Chen, M. Marquis, K. Averyt, M. Tignor, and H. L. Miller Jr., Eds., 2007: Climate Change 2007: The Physical Science Basis. Cambridge University Press, 996 pp.

Son, S. W., and Coauthors, 2008: The impact of stratospheric ozone recovery on the Southern Hemisphere westerly jet. Science, 320, 1486-1489, doi:10.1126/science.1155939. 
Taylor, K. E., R. J. Stouffer, and G. A. Meehl, 2012: An overview of CMIP5 and the experiment design. Bull. Amer. Meteor. Soc., 93, 485-498.

Vecchi, G. A., and B. J. Soden, 2007: Global warming and the weakening of the tropical circulation. J. Climate, 20, 43164340.

Velders, G. J. M., S. O. Andersen, J. S. Daniel, D. W. Fahey, and M. McFarland, 2007: The importance of the Montreal Protocol in protecting climate. Proc. Natl. Acad. Sci. USA, 104, 4814-4819.

—_, and Coauthors, 2012: Preserving Montreal Protocol climate benefits by limiting HFCs. Science, 335, 922-923.

WMO, 2011: Scientific assessment of ozone depletion: 2010. Global Ozone Research and Monitoring Project Rep. 52, WMO, $516 \mathrm{pp}$.

Wu, Y., R. Seager, M. Ting, N. H. Naik, and T. A. Shaw, 2012: Atmospheric circulation response to an instantaneous doubling of carbon dioxide. Part I: Model experiments and transient thermal response in the troposphere. J. Climate, 25, 28622879.

,-- , T. A. Shaw, M. Ting, and N. Naik, 2013: Atmospheric circulation response to an instantaneous doubling of carbon dioxide. Part II: Atmospheric transient adjustment and its dynamics. J. Climate, 26, 918-935.

Wyant, M. C., C. S. Bretherton, P. N. Blossey, and M. Khairoutdinov, 2012: Fast cloud adjustment to increasing $\mathrm{CO}_{2}$ in a superparameterized climate model. J. Adv. Model. Earth Syst., 4, M05001, doi:10.1029/2011MS000092.

Yang, E.-S., D. M. Cunnold, R. J. Salawitch, M. P. McCormick, I. J. Russell, J. M. Zawodny, S. Oltmans, and M. J. Newchurch, 2006: Attribution of recovery in lower-stratospheric ozone. J. Geophys. Res., 111, D17309, doi:10.1029/2005JD006371.

,-- M. J. Newchurch, R. J. Salawitch, M. P. McCormick, I. J. M. Russell, J. M. Zawodny, and S. J. Oltmans, 2008: First stage of Antarctic ozone recovery. J. Geophys. Res., 113, D20308, doi:10.1029/2007JD009675. 